\title{
What is Middle Class about the Middle Classes around the World?
}

\author{
Abhijit V. Banerjee and Esther Duflo \\ Abhijit V. Banerjee and Esther Duflo are both Professors of Economics and Directors of the Abdul \\ Latif Jameel Poverty Action Lab, Massachusetts Institute of Technology, Cambridge, \\ Massachusetts.
}

We expect a lot from the middle classes. Jim Frederick, writing in Time magazine in 2002, stated: "China's burgeoning middle class holds the key to the future of the country." In a more academic vein, Easterly (2001) concludes, based on a comparison of a large number of countries, that countries that have a larger middle class tend to grow faster, at least if they are not too ethnically diverse. In another article, Birdsall, Graham, and Pettinato (2000) rue the shrinking of the middle class- "the backbone of both the market economy and of democracy in most advanced societies"-in the face of burgeoning globalization. The economic historian David Landes, writing about The Wealth and Poverty of Nations (1998), explains England's early ascendancy in terms of "the great English middle class" of the eighteenth and nineteenth centuries.

Of course, there is nothing new about this faith in the middle class-it follows a long line of theorizing going back, at least, to Max Weber (1905). At least three distinct arguments are traditionally made. In one, new entrepreneurs armed with a capacity and a tolerance for delayed gratification emerge from the middle class and create employment and productivity growth for the rest of society (for a formalization of this argument, see Acemoglu and Zilibotti, 1997). In a second, perhaps more conventional view, the middle class is primarily a source of vital inputs for the entrepreneurial class: it is their "middle class values"- their emphasis on the accumulation of human capital and savings-that makes them central to the process of capitalist accumulation (for example, Doepke and Zilibotti, 2005, 2007). The third view, a staple of the business press, emphasizes the middle class consumer, the consumer who is willing to pay a little extra for quality. In this view, the middle class demand for quality consumer goods feeds investment in production and marketing, which in turn raises income levels for everyone (Murphy, Shleifer, and Vishny, 1989). ${ }^{1}$

This essay asks what we should make of these arguments in the context of today's developing countries. Starting from data on patterns of consumption and investment by the middle class, we look for what is distinct about the global middle class, especially when compared to the global poor-defined as those whose per capita daily consumption, valued at purchasing power parity exchange rates, is below $\$ 2$ a day-who were the subject of a previous essay in this journal (Banerjee and Duflo, 2007b). In particular, is there anything special about the way the middle class spend their money, earn their incomes, or bring up their children?

\section{Identifying the Middle Class}

No global dataset exists to answer these kinds of detailed questions on a worldwide basis. However, a growing number of household surveys have been done in low- and middle-income countries around the world. Thus, we turn to the household surveys for 13 countries:

\footnotetext{
${ }^{1}$ There is also an argument that the middle classes are important for development of democracy, but given the nature of our data, we will have nothing useful to say about this.
} 
Guatemala, India, Indonesia, Ivory Coast, Mexico, Nicaragua, Panama, Pakistan, Papua New Guinea, Peru, South Africa, Tanzania, and East Timor. From each of them, we extracted the same information on two groups of households: households whose daily per capita expenditures valued at purchasing power parity are between $\$ 2$ and $\$ 4$, and those households between $\$ 6$ and $\$ 10$. These are the groups that we will call the middle class. Figure 1 shows the average consumption in each of the groups we will consider, in rural and urban areas. The choice of these two income groups is (obviously) ad hoc, though, as we will argue in a moment, both broadly fit the definitions other people have used. The reason to pick groups at the two ends of the middle class is to get a sense of the extent to which our findings are driven by the choice of the comparison group and to observe whether the trends we observe between the poor and the bottom of the middle class continues as we move towards the top of that category.

The surveys we use include the Living Standard Measurement Surveys (LSMS), conducted with support from the World Bank; the Family Life Surveys, conducted by the RAND Corporation; and two surveys of regions in India-Udaipur and Hyderabad-that we conducted with coauthors. Detailed tables presenting all the data discussed in this paper on a country-by-country basis is presented in an on-line appendix available with this paper at 〈http://www.e-jep.org〉. Both the LSMS and the Rand surveys are generally considered to be very high-quality data and are extensively used both to compute countrywide statistics (for example, the poverty level) and as data sets for studies of household behavior (Deaton, 1997; Glewwe and Grosh, 1999).

In what sense should people living on between $\$ 2$ and $\$ 10$ per day be called "middle class"? These households are still very poor by developed country standards; the poverty line in the United States in 2006 for someone who lives in a family of five, for example, was $\$ 24,385$, which when divided by five people in the family and 365 days in a year, works out to be about $\$ 13$ per day.

On the other hand, the middle class in these countries are clearly much better off than the poor, who live on less than $\$ 1$ or $\$ 2$ a day. Easterly (2001) defines the "middle class" as those lying between the $20^{\text {th }}$ and $80^{\text {th }}$ percentile on the consumption distribution. Table 1 shows the position of the $\$ 1, \$ 2, \$ 4, \$ 6$, and $\$ 10$ lines compared to the various percentile cut-offs in the income distribution of the 13 countries in our sample. For surveys meant to be representative of a country's population, this information is generated directly from the survey (although many argue that household surveys in low-income countries probably do not include enough of those with very high incomes to categorize this group). For countries where the survey focuses on those with lower income levels and so is not representative of the entire population, we used data from the World Bank "Povcalnet" website.

In all 13 of our studied countries, except for the rural parts of three of them (India, Pakistan, and Panama), the $\$ 2$ to $\$ 4$ per day category comprises between 23 and 40 percent of the population, and is primarily composed of those between the $20^{\text {th }}$ and the $80^{\text {th }}$ percentile of income. In rural India and Pakistan, the $\$ 2$ line lies above the $80^{\text {th }}$ percentile of consumption, so that the $\$ 2$ to $\$ 4$ category is richer than the middle class by Easterly's (2001) definition. But even in these countries, it seems reasonable to think of this group as a middle class, especially since it seems hard to imagine calling them rich. Panama is the one country in our sample where most of those whose consumption lies between $\$ 2$ and $\$ 4$ are actually poorer than the middle class as defined by Easterly.

The \$6 to \$10 group is smaller in most countries, and in many of our countries, those belonging to this group are above the $80^{\text {th }}$ percentile of incomes. For example, in India, Indonesia, Ivory Coast, Pakistan, Tanzania, and East Timor, the $\$ 6$ line is located above the $90^{\text {th }}$ percentile. In Guatemala, Nicaragua, Papua New Guinea, and Guatemala, it is around the $80^{\text {th }}$ percentile, 
while the $\$ 10$ line is around the $90^{\text {th }}$ percentile. It is only in the three richest countries in our study-Mexico, Panama, and South Africa — that the bulk of the $\$ 6$ to $\$ 10$ category has consumption per capita lower than the $80^{\text {th }}$ percentile. Again, it seems hard to imagine referring to people living on $\$ 6$ or $\$ 10$ a day as "rich," given how poor they are by the standards of highincome countries, which suggests that it is reasonable to bring them into a more inclusive definition of the middle class. However, it is worth keeping in mind in what follows that they are a substantially richer group, near the top of the income distribution in their countries.

Other definitions of the middle class provide similar results. For example, Birdsall, Graham, and Pettinato (2000) define the middle class as those between 75 and 125 percent of median per capita income. By this definition as well, the $\$ 2-\$ 4$ category seems to represent the middle class. For example, in Mexico, they calculate that the middle class would include anyone with a per capita income between $\$ 1,000$ and $\$ 1,666$ which, accounting for the fact that this is income and not consumption, is similar to our $\$ 2-\$ 4$ per day category. In Peru, the corresponding group is between $\$ 908$ and $\$ 1,513$ in per capita annual income, which also fits very well the \$2-\$4 group. In Panama, on the other hand, the middle class is again according to this definition significantly richer-between $\$ 1,718$ and $\$ 2,864$ - which puts this group at the low end of the $\$ 6-\$ 10$ per day group.

Finally, how does our population compare with the English middle class of the nineteenth century, which, according to Landes (1998), was the engine of British economic growth? Boot (1999) uses data about clerks in the English East India Company to come up with a measure of middle class incomes in the high years of the industrial revolution in England. By his calculations, around 1825 the average clerk who had between 11 and 15 years of experience and hence was around 31-35 years of age (most people joined when they were about 20) earned about 400 British pounds a year. Converted into 1993 dollars, this corresponds to $\$ 23,200$ a year, or $\$ 63$ a day, for an entire family. ${ }^{2}$ The typical family described in the article consisted of one earner, his wife, and his three children. Per capita earnings therefore work out to be about $\$ 12.50$ a day per person, which given that these families probably saved quite a bit, puts them only a little above $\$ 10$ daily per capita expenditure, at the top of our income range.

\section{The Middle Class Consumer}

\section{Eating and Drinking}

As observed more than 100 years ago by Engel (1895), the share of the budget spent on food falls with increases in the standard of living. In rural Guatemala, for example, the share of the budget spent on food falls from 65 percent among the extremely poor on less than $\$ 1$ per day to 13.5 percent among those with daily per capita expenditures between $\$ 6$ and $\$ 10$. While the Guatemala example is extreme, in other countries the share spent on food varies between 35 and 65 percent among rural households with daily per capita expenditures of $\$ 6-\$ 10$, while it is between 50 and 77 percent among those with daily per capita expenditures below $\$ 1$. Figure 2 shows the weighted average across the countries in our sample, using as weights the country population in each specific consumption bracket. The patterns are similar in urban areas. This decline in the share of income spent on food is also accompanied in general by a shift toward better tasting, more expensive foods, so that the number of calories consumed grows more slowly than spending on food (Deaton, 1997).

No comparable pattern exists for alcohol and tobacco: the share of income spent on these goods goes up in some countries and down in others as incomes rise. There are opposing forces at

\footnotetext{
2 According to inflation tables reported by Officer (2007), it appears that one 1825 pound was worth about 441993 pounds. Hence, 400 pounds in 1825 equals about 17,600 pounds in 1993, which using the 1993 dollar-pound exchange rate of about 1.55 and the standard purchasing power parity correction of .85 for the United Kingdom, works out to be about $\$ 23,200$ a year.
} 
work. On the one hand, alcohol and tobacco are luxury goods. On the other hand, the middle class may also be more conscious of the health and social consequences of such spending (though they do end up spending more). Moreover, it is possible to make the argument (though this remains, at best, a hypothesis) that the poor are more subject to the kinds of acute stress that might lead to substance abuse.

\section{Entertainment}

As incomes rise, some of the resources freed up by the lower share of income going towards food are spent on entertainment. The share of expenditure devoted to entertainment rises with income, increasing from next to zero among the extremely poor to between 1 and 5 percent among those with daily per capita expenditures between $\$ 6$ and $\$ 10$, both in rural and in urban areas. The increase is about half as much among those with daily per capita expenditures between $\$ 2$ and $\$ 4$. The share of income spent on festivals increases with the standard of living as well.

Similarly, as incomes rise, there is also a very sharp increase in the fraction of households that own a television, as shown in Figure 3. In the urban areas of most of our 13 countries, over 80 percent of the households with daily per capita expenditures between $\$ 6$ and $\$ 10$ have televisions (the exceptions are East Timor and Tanzania, where television ownership remains low), while the corresponding share is between 25 and 63 percent for the extremely poor. The same is true in rural areas, where the share of television ownership is less than 26 percent among the extremely poor, and between 35 and 76 percent in the \$6-\$10 category (except in Papua New Guinea and Tanzania; no data is available for East Timor).

\section{Education and Health Care}

In most countries (with the exception of Panama), the share of budget devoted to educational spending remains more or less constant as the standard of living rises. In other countries, the share of the budget going to educational spending is sometimes constant, and sometimes rising. For example, in Nicaragua, the rise is from 5.6 percent among the extremely poor to 8.6 percent for those with daily per capita expenditures between $\$ 2$ and $\$ 4$ and to 9 percent for those with daily per capita expenditures between $\$ 6$ and $\$ 10$. An increased share of spending going to education as consumption rises is also found in Mexico, Peru, Indonesia, and Panama.

The pattern is clearer for health. Health care spending as a share of daily per capita expenditures rises in most countries, in both rural and urban areas; for example, in rural Mexico it goes from 2.2 to more than 4.9 percent, in urban Indonesia from 1.4 to 3.4 percent, in Hyderabad from 5 to 17 percent.

\section{Domestic Infrastructure}

Not surprisingly, households with higher incomes live in bigger houses-for example those with daily consumption per capital between $\$ 6$ and $\$ 10$ live in houses that have between 2.1 (rural Mexico) and 6.0 (rural Indonesia) rooms. In most countries, they have about 1.5 extra rooms than those of the extremely poor, despite the fact, to be discussed later, that their families tend to be smaller.

More importantly, the basic amenities in the homes of the middle class are completely different than in those of the poor. While the poor often live without access to electricity, running water, or a latrine, the fraction of households with tap water at home increases with daily per capita expenditures in most countries and in some countries by a lot: from 1 percent for the extremely poor to 19.7 percent for those with daily per capita expenditures between $\$ 6$ and $\$ 10$ in rural Ivory Coast; from 18 to 48 percent for these consumption groups in Nicaragua; and from 5 to 40 percent for these two groups in rural South Africa. In the urban areas of five out of the eight 
countries for which we have data, 70 percent or more of the households with daily per capita expenditures of \$6-\$10 have tap water, whereas for the extremely poor, the share is below 50 percent in all countries but two. Figure 4 shows the weighted average across the sample.

The same pattern holds for latrines, where the share of those who have one among the urban households with daily per capita expenditures of $\$ 6-\$ 10$ is above 80 percent in seven of the nine countries, and also for electricity, where the share of urban households that have access to electricity in this group is above 90 percent in seven of the studied countries.

It seems clear that the middle class pursues what is conventionally known as better "quality of life"-better health care for the family and more expensive education for the children (see the later section on "Investing in Human Capital" for more details), as well as more and better housing, more expensive eatables and more entertainment, tobacco, and alcohol. Despite the middle class's reputation for thrift, some "frivolous" consumption is as middle class as a commitment to education or health care.

While our data does not permit us to look more carefully into this question (we cannot, for example, look at the demand for brand-named goods or the susceptibility to "life-style" advertising), the evidence is consistent with the hope pinned on the middle class in developing countries by so many marketing experts.

\section{The Middle Class and the Poor: What They Have in Common}

The middle class live very differently from the poor in so many ways, so it is striking how much the poor and middle class within a particular country have in common in terms of how budgets are allocated. For example, the relative ranking of countries by the fraction of income spent on food is very similar across the various income categories. Countries that are below the median in terms of the budget share that those under $\$ 1$ a day in rural areas devote to food, are Guatemala, India (Udaipur), Ivory Coast, Mexico, Nicaragua, and Pakistan. The list of countries below the median in terms of the budget share that the \$2-\$4 category in rural areas devotes to food is almost identical, except that Panama comes in place of Ivory Coast. The list of countries that are below the median in terms of the food share of those under $\$ 1$ a day in urban areas is also similar: out of the four countries in that list, three (India, Mexico, and Nicaragua) are also in the corresponding rural list, despite the fact that people living in urban areas typically spend much less on food than their rural counterparts.

The same point could be made using any of the other categories of spending: for tobacco and alcohol spending, the bottom five countries are East Timor, Guatemala, Peru, Nicaragua, and South Africa in the rural "under \$1" category and East Timor, Guatemala, Peru, Nicaragua, and Pakistan in the rural \$2-\$4 group. The corresponding countries in the urban "under \$1" group are East Timor, Nicaragua, Peru, and India (Hyderabad). For education, the bottom six countries both in the rural "under \$1" category and the rural \$2-\$4 category are Guatemala, East Timor, Peru, Papua New Guinea, South Africa, and India (Udaipur). The corresponding countries in the urban $\$ 1$ list are East Timor, Nicaragua, Peru, and India. For health care, the only difference between the list of the five lowest countries for the rural $\$ 1$ category and for the rural \$2-\$4 category is that Ivory Coast comes in the place of Mexico. Many such similarities can easily be identified.

Why should being from the same country be so important? After all, there are enormous differences within countries in how people live - between, say, the mansions of Mumbai and the hovels of Hyderabad. A possible answer is that everyone we look at, including the \$6-\$10 group, is still poor. But this story does not quite add up. In South Africa, for example, the average rural person who spends $\$ 2$ per day spends about 67 percent of that amount on food, which suggests that one can more or less survive while spending about $\$ 1.30$ per day per person 
on food in that country. Someone who is living on $\$ 8$ a day in the same country spends roughly $\$ 3.50$ per day on food (using the 44 percent average food share for those between $\$ 6$ and $\$ 10$ ). Thus, that household could save about $\$ 2.20$ a day by buying cheaper food. For a family of five, this savings adds up to $\$ 11$ a day, or roughly $\$ 4,000$ a year. This amount is far from negligible. The income of the middle class (especially at the upper range) give the middle class options to consume very differently from the poor, if they so chose.

Why then do we see a connection between the consumption habits of the poor and the middle class within the same country? One depressing possibility is that each country has unique flaws in its data collection apparatus, which create the appearance of patterns that seem to affect everyone within the country. Similarly, perhaps certain reporting biases systematically vary across countries. For example, in Pakistan, there may be some reluctance to admit consumption habits that are proscribed by Islam. However, as we indicated, the Living Standard Measurement Surveys benefit from the World Bank's oversight and are generally considered to be of good quality (Glewwe and Grosh, 1999; Deaton, 1997). So data quality probably does not explain everything.

Of course, there could also be national differences in taste that, in turn, could be a result of geography. For example, coca leaves grow in Peru, which may be why everyone smokes less tobacco and drinks less alcohol there. There are almost surely some common norms about appropriate forms of consumption, though whether that reflects shared intrinsic values or the pressure to keep up appearances on the part of the poor remains an open question. For example, the anthropological literature on South Africa suggests that the often extravagant funerals are a result of the middle class setting norms that the poor feel pressured to emulate.

Another idea, one that comes naturally to economists, is that everyone within a country behaves in a relatively similar way because they are all responding to the same relative prices. In South Africa, $\$ 4,000$ in savings is equivalent to about $\$ 2,000$ in purchasing power parity terms to buy traded goods that sell on the world market. In India, the same amount will only buy $\$ 800$ worth of the traded goods that sell on the world market. In other words, if one family in South Africa and another in India have the same amount to spend, the one in India can afford much less in terms of traded goods - but the Indian family is compensated by the fact that, relative to South Africa, goods that do not get traded on the world market can be bought much more cheaply. Hence, we might expect Indians to be more inclined towards nontraded goods (like eating out, locally made cigarettes, and traditional garments) while South Africans lean towards traded goods (like televisions, refrigerators, and certain kinds of edibles).

Price differences can also result from institutional differences. The share of expenditures on health care is so very low in Mexico, Peru, and South Africa not because people in these countries are especially healthy (or because they don't care about their health), but because decent public health care is available more or less for free. On the other side, poor performance of the nominally free public health care system probably explains why in India and in Pakistan even the poorest spend quite a bit on health care.

\section{Earning a Living Occupational Patterns}

At first blush, the occupational patterns of the middle class seem surprisingly similar to those of the poor.

One difference is that in rural areas, the middle class seem less directly connected to agriculture than those with low incomes. Strikingly, the rural middle class are actually less likely to own land than the rural poor in all but three of our countries. Correspondingly, the middle class are 
also less likely to be self-employed in agriculture. For example, in Nicaragua, the fraction of households self-employed in agriculture goes from 56 percent among the extremely poor (daily per capita expenditures below $\$ 1$ per day) to 36 percent for those with daily per capita expenditures between $\$ 2$ and $\$ 4$; in Panama, the comparable figures are 65 and 32 percent (and it drops further to 18 percent among those with daily per capita expenditure between $\$ 6$ and $\$ 10)$. The middle class are not working for a wage in agriculture either: the fraction of people who are earning a wage in agriculture among those with daily per capita expenditures between $\$ 6$ and $\$ 10$ falls to below 5 percent everywhere but Guatemala (20 percent) and Ivory Coast (60 percent).

How do middle class households make a living in rural areas if not from agriculture? In some countries, the rural middle class are local entrepreneurs: 52 percent of those with daily per capita expenditures between $\$ 6$ and $\$ 10$ in rural areas are self-employed outside agriculture in Indonesia (versus 36 percent among those with daily per capita expenditures below $\$ 1$ ). The rural middle class are also more likely to be entrepreneurs outside agriculture in Udaipur (India), Nicaragua, Panama, and South Africa. Figure 5 shows that overall, the share of households with a nonagricultural business increases with income in rural areas. Yet, in some countries, the rural middle class are no more likely to own a business than those with low incomes. For example, in Guatemala and Mexico, the percentages of each group owning a business are roughly constant. In those countries, the rural middle class are typically salary earners working outside of agriculture. Of those with daily per capita expenditures between $\$ 6$ and $\$ 10,52$ percent are working for a wage outside agriculture in Ivory Coast, 73 percent in Guatemala, and 51 percent in Mexico.

In urban areas, the broad occupation patterns are remarkably similar between the poor and the middle class. The share of entrepreneurs stays roughly the same, as does the share of employees. The middle class is also quite diversified: depending on the country, 14 percent to 36 percent of the households receive incomes from multiple sectors.

\section{The Middle-Class Entrepreneur}

The striking fact about business investments, especially given the differences in the potential to save, is how little difference there is between those of the middle class and those of the poor.

As we saw above, the middle class is about as likely to be business owners as the poor, and less likely to be in the farming business when they live in rural areas. When the middle class do operate a nonagricultural business, the type of business they operate is also not very different from that of the poor. The number of employees who are not family members is still tiny: specifically, the businesses of those with daily per capita expenditures between $\$ 6$ and $\$ 10$ have on average only 0.5 to 1 more paid employee, as shown in Figure 6. Businesses owned by the middle class still seem to operate with very little in the way of assets, such as machinery or a form of transport. For example, unlike radios and televisions, ownership of bicycles does not increase substantially as incomes rise from poor to middle class. In fact, bicycle ownership actually goes down between " $\$ 2$ to $\$ 4$ " households and " $\$ 6$ to $\$ 10$ " households in some countries.

What kinds of businesses do those with daily per capita expenditures between $\$ 2$ and $\$ 4$ in Hyderabad run? In our data 21 percent are general stores, 17 percent are tailor shops, 8.5 percent are telephone booths, and 8 percent are fruit or vegetable businesses. The rest are spread across a wide variety of occupations including rag-picking, selling milk, and collecting cow dung. These are also the most common businesses among those with consumption under $\$ 2$ a day, though the poor are spread across an even wider range of activities: for the poor, stores are only 13 percent of all businesses; 13 percent are tailors; and 5 percent are phone booth operators. 
General stores like the ones we see in Hyderabad are a familiar sight all over India, urban and rural, and in most other developing countries. Each village has several such stores, typically run out of a corner of somebody's house or a rented kiosk by the road, often little bigger than four feet wide and four feet deep. Table 2 shows the inventory of one such shop in a village on the outskirts of the town of Gulbarga in Northern Karnataka, about a five-hour drive from Hyderabad. The family runs a metal scrap business and the household's daily consumption puts it into the $\$ 2$ to $\$ 4$ category. The store consists of a set of plastic jars arranged on top of one another in a dimly lit side-entrance to the house. During the two hours we spent with household, we saw two clients. One bought a single cigarette; the other a box of incense. Given this level of business, the very modest inventory detailed in Table 2 probably makes sense, though from the owner's point of view it would seem to be a problem that the shop was selling exactly the same things that one would find in all the other stores in the village, often within a few hundred feet of each other (indeed, with some small local variations, this is what one would find at any of the millions of similar venues elsewhere in India). In other words, there seemed to be nothing that would make one want to come to this particular store, either in terms of its product lines or the shopping environment (though in the personality of the owner, a vivacious woman of around 30, this particular shop seemed to have a potential commercial advantage). The business seemed to be not much more than a way to allow the woman to earn a little extra cash while she takes care of her family, on a fairly minimal outlay.

This sense of getting something without a large resource commitment appears to infuse most businesses of the middle class. In Hyderabad, as elsewhere, the businesses run by the middle class have very few employees: the maximum number was three; and at the $95^{\text {th }}$ percentile, the number of employees was one. These businesses are mostly run by one person, though 25 percent of the businesses have two or three household members working, although the other household members usually work only an hour or two each day.

On the other hand, owners commit a lot of time to the businesses they own, at least when they work full time. Sixty-two percent of the businesses in the sample are operated full time by the owner (in the other cases, business owners spread their activities around several jobs). Where the owners work full time, they report very long hours: in our data, the number of hours worked in the last week ranges between 40 hours per week and 119 hours per week. The mean is 72 , and the median is 77 , which means more than ten hours a day, seven days a week. Some businesses, like the shop we saw in Gulbarga, are part-time businesses, one of the many activities the owner undertakes: part-time owners averaged 24 hours per week.

The average monthly sales of these businesses in Hyderabad are 1,751 rupees (\$125 in 1993 PPP dollars), and the median is Rs 3,600 (\$257). The average monthly profit, after deducting any rents they pay but not including the unpaid time spent by household members, is Rs 1,859 (about \$133), and the median is Rs 1,035 (about \$74), a real but modest gain. Fifteen percent of the businesses have lost money in the last month, after subtracting rents. When we value the hours spent by household members, even at the low rate of Rs 8 an hour (which would give someone close to the minimum wage for an eight-hour day), the average profits turn mildly negative. However, running one's own business offers flexibility and the ability to do other things at the same time, such as taking care of children. The woman who owned the shop outside Gulbarga could afford to spend two hours talking to us while running her store, with only occasional interruptions.

Working on their own thus allows owners to make more or less the same amount of money than if they worked for someone else, in exchange for longer but less intensive hours. But this is of course assuming they could find such a job. These businesses might be less an engine of growth than a means of sustenance, a way of "buying a job." 
There may also be an important gender dimension to these businesses. In an interesting randomized experiment (described below), De Mel, McKenzie, and Woodruff (2007b) contrast the returns to capital for businesses owned by men and women. They find much lower rates of return for women. The business of middle class women may be seen as a complement to the men's activities, compatible with child-rearing. On the other hand, a woman may also get something out of having her own little operation that she could not get otherwise-some cash of her own, an opportunity to go out occasionally, a chance to meet other people, a challenge. In other words, neither side may see the extra work for what it looks like to us-hours of avoidable tedium.

\section{Credit Constraints?}

Despite these low profits, the returns to investing in the capital stock of such firms seem quite high: De Mel, McKenzie, and Woodruff (2007a) gave randomly selected owners of firms in Sri Lanka that were very similar to these an infusion of capital equal to 100 to 200 percent of the capital stock and found very high returns to capital on average-over 5 percent per month (although as we just noted, the results were different for men and women). This result is consistent with the fact that when these businesses borrow, the interest rate is on average 3.84 percent per month.

An obvious interpretation of this finding is that these businesses are severely undercapitalized, because the middle class, much like the poor, does not have particularly good access to capital. The reason why average returns are low even though the marginal returns are very high (at least for businesses operated by men) is that running a business has significant fixed costs (including the cost of the owner's time), and a business needs to sell enough to cover these fixed costs before it can be profitable. The shop in Gulbarga was a case in point. With so little to sell, there was very little our host could have done to increase her productivity. In sum, the middle class does not run businesses that are very different from those of the poor. And usually it is not the money they make in those businesses that makes them middle class.

Yet compared to the poor, the middle class has substantially better access to formal sources of credit. While the fraction of households who are borrowing from anyone stays roughly constant across income groups, the fraction of those loans that have been extended by a bank is larger for the middle class, and especially for urban households (although it varies a lot from country to country). For example, in urban Indonesia, the share of loans to households extended by banks is 23 percent for households with daily per capita expenditures below $\$ 1$, and it is 74 percent for households with daily per capita expenditures between $\$ 6$ and $\$ 10$. In Pakistan, the share goes up from 1.6 percent for the poorest to 10 percent for households with daily per capita expenditures between $\$ 2$ and $\$ 4$.

Of course, the middle class may still lack as much access to financing as they would want. We did find that in Hyderabad, those among the middle class who borrow for their businesses pay rates that are comparable to those paid by the poor (about 4 percent per month), though probably for larger loans. In addition, it is possible that much of their bank credit is tied to specific purchases of consumer durables and cannot be diverted to starting or expanding a business.

However, the mystery does not entirely end here. The lack of access to capital and the resulting undercapitalization raises a further conundrum: Why don't those in the middle class save more in order to grow their businesses? Clearly, for someone who is paying 4 percent per month on a loan, savings would have a return of at least 4 percent per month (depending on whether they use the money to pay down the loan or invest more). At those lucrative rates, saving most certainly appears worthwhile. 
This puzzle is especially sharp because the middle class accumulates other assets. Middle class people buy durables like a television and/or a radio. They own larger houses with better amenities. They are much more likely to have a savings account: in rural areas in all countries but Ivory Coast, where it is higher, about one-third of the middle class households have a savings account. In urban areas, the share is larger. The middle class spends a lot on health and education.

Yet businesses owned by the middle class remain resolutely small, even as their health care spending, for example, explodes. In Hyderabad, the poor spend 5 percent of their daily per capita expenditures on health care. The middle class, defined as those between $\$ 2$ and $\$ 4$ daily per capita expenditures, spends about 10 percent. If the middle class families instead spent 5 percent of their overall budget on health care, like the poor, they would still be spending much more per capita in absolute terms, because they are richer and have smaller families. By doing this, a family of five in the $\$ 2-\$ 4$ a day category could save enough to allow the shop outside Gulbarga that we described earlier to double the value of its (rather meager) stock. A family with higher income could obviously do even better. If these middle class families do not build up their enterprises, it is because it is not their priority: human capital investments seem to be more important to them.

It is difficult, therefore, to view the middle class as particularly entrepreneurial. There are no doubt many successful entrepreneurs who have come out of the middle class, but for the median middle class family that owns a business, the business is just a source of some additional cash and not a huge amount at that.

That is not to say that the emergence of new entrepreneurs is not an important part of the growth process. But it is possible that the profits that the typical family-based businesses can aspire to may be too small in most cases to justify putting too much effort into them. We have argued that the Indian economy seems to be characterized by high efficiency gains at high levels of capitalization and fast-diminishing returns for medium-sized businesses (Banerjee and Duflo, 2005). It is possible that to be a really effective entrepreneur in today's economy one has to set up a business that is much bigger than what an average middle class family can afford. To find the family businesses that are really dynamic and successful, one might have to look among families that are significantly richer than what we are calling the middle class, or among ones that have the right social connections. For most of our families (there are always a few exceptions, those who are especially lucky or talented), it may well be that focusing on getting the best education for their children is the better investment.

\section{Salaried Employment}

If the middle class is not primarily made of successful entrepreneurs, what is distinctive about the way they earn their money?

The key distinction between the middle class and the poor is who they are working for, and on what terms. While the household surveys typically lump together daily and casual laborers with salaried workers into one category (wage workers), the distinction between those two forms of employment is crucial. Casual workers work on a farm, a construction site, a truck or a shop, on short-term contracts with no job security. The hours worked by the poor often fluctuate tremendously over time with the availability of jobs, and the poor frequently migrate temporarily to find a job. This makes it harder for them to acquire occupation-specific skills. In addition, these jobs do not come with health or retirement benefits, which adds to the risk the poor have to bear.

In contrast, those in the middle class are much more likely to be in relatively secure, salaried jobs. Most surveys do not attempt to classify the job by degree of "job security," or 
formalization, but a convenient proxy is the frequency of payment. While casual jobs are often paid daily or hourly, regular jobs are paid weekly or monthly.

Assuming that this is a reasonable proxy, it is clear that the middle class is much more likely to hold salaried jobs than the poor. Figure 7 shows the weighted average across all the countries in the sample. In urban areas, for all the countries for which we have these data, between 67 and 99 percent of those in the $\$ 2-\$ 4$ category are paid weekly or monthly. The proportion is above 89 percent in four countries out of the seven for which we have data. The fraction is even higher among those in the $\$ 6-\$ 10$ category. In contrast, it is between 38 and 83 percent for those earning less than a dollar a day. In rural areas, the pattern is similar (the only exceptions are in Indonesia and South Africa, where only 41 percent of those in the \$2-\$4 category are paid weekly or monthly).

Having a regular, well-paying, salaried job may thus be the most important difference between the poor and the middle class. There are very few people who live on more than $\$ 4$ per day in our Udaipur sample, but we accidentally met several of them on one of our trips. Their village was about an hour from Udaipur city through largely deserted country like many other villages in our sample, though in this case there was a paved road leading up to the village. Signs of their relative well-being were apparent: a corrugated metal roof, two motorcycles in the courtyard, and a teenager in a starched school uniform. It turns out that, in the families we interviewed in the village, everyone of working age was working in the local zinc factory.

We were told that many years ago the father of the current head of one of the households (a man in his late 50s) was hired to work in the kitchen of the factory, and then went on to work on the factory floor. His son (the gentleman who was talking to us) was part of the first batch of eight boys in the village to complete grade 10. After finishing school, he also went on to work in the zinc factory, where he became a foreman. His two sons both finished high school. One of them works in the same zinc factory and the other shuttles between the village and temporary jobs in Ahmedabad, the capital of the neighboring state of Gujarat. He also has two daughters, who completed high school before getting married. He is now retired.

For this family, the fact that the zinc factory was set up near their village was an original stroke of good luck, which set off a virtuous circle of human capital investment and progression up the employment ladder. Unfortunately, there is little in our data that helps us understand how general this phenomenon might be. Do middle class people get the better jobs because they are more educated, more talented, more willing to make investments, or is a lot of it due to luck? A study by Foster and Rosenzweig (forthcoming) shows that the role of factory employment in promoting wage growth in Indian villages goes far beyond this particular anecdote. Using a panel data set representative of India covering 30 years (1969-1999), they examine the impact on poverty and inequality of factory employment, growth in local businesses, and agricultural growth. Over this period, India experienced both fast growth in the productivity of agriculture and a very rapid increase in factory employment in rural areas, in part due to a pro-rural investment policy. Rural factory employment increased tenfold between 1980 and 1999. In 1999 , about half of the villages in their sample were located near a factory, and in those villages, 10 percent of the male labor was employed at a factory. Foster and Rosenzweig show that these factories tended to locate themselves in places where wages were low (so that they were actually less likely to be set up in places that had experienced high agricultural productivity growth) and more likely to be in states were the labor laws were more favorable to employers (according to the index developed by Besley and Burgess, 2004). Moreover, they mainly employed unskilled labor. Household-level data suggest that neither education (availability of schools in the past) nor land-ownership predict employment in a factory. 
Foster and Rosenzweig's (forthcoming) estimates of the impact of agricultural productivity growth and factory employment on income show that both forms of growth reduce poverty, but that the growth in rural factory employment over the 1982-1999 period in India accounts for twice the share of rural wage growth compared to the improvement in agricultural yields over the same period. They also show that because these factories employ low-skilled workers and settle in poorer areas, they contribute to the decline of both inter-village and intra-village inequality.

This analysis suggests that when people get a job because a factory starts in one village rather than in another, it has a significant effect on poverty. While we are certainly not suggesting that this is the only reason why the middle class has better jobs, luck clearly plays a major role in getting a virtuous circle started.

\section{Migration and Labor Supply}

Migration decisions of the middle class differ substantially from those of the extremely poor; unlike the poor, the middle class are actually quite likely to have moved from elsewhere to the areas where they now work. In urban areas, the share of people who have migrated since birth among those with daily per capita expenditures of \$6-\$10 ranges between 31 percent in Pakistan and 77 percent in East Timor; for those with daily per capita expenditures of \$2-\$4, it ranges between 30.5 percent in Pakistan and 75 percent in East Timor, but only between 16 and 60 percent among the poor. Even in rural areas, a much higher fraction of the middle class has permanently changed location since birth for work reasons. Also, while temporary migration remains as important a phenomenon for the middle class as it is for the poor (about 52 percent of the households in Udaipur who live on more than $\$ 2$ a day have had someone temporarily migrate over the last year), migration takes the middle class further (64 percent of temporary migrants from households living on more than $\$ 2$ a day have gone to a city outside Rajasthan, compared to 42 percent for the extremely poor) and their migration lasts longer (twice as long as that of the very poor).

Both of these facts suggest a greater commitment to the job worked away from home and a greater investment in finding the right job (one reason why a person holds a better job may be that the person migrated to get it). However, these facts do not necessarily imply greater intrinsic motivation. It could also be that the opportunities to migrate to get a better job are rare, and those who get such an opportunity take it and then do better. Or the middle class may be compelled to migrate because they are better educated and there may not be many jobs commensurate with their particular education in their home town or village. Also, since we observe the economic status of an individual's household after he or she has migrated, we cannot distinguish between the effects of migration per se and the differences between people who migrate.

Another difference shows up in the hours of work. In rural areas, conditional on having worked at least part of the week, men living in households with daily per capita expenditures of $\$ 2$ $\$ 4$ work more hours per week than the extremely poor in all countries. The difference is around three hours per week-in total those at \$2-\$4 work between 40 hours a week (Panama) and 55 hours (South Africa). The same is largely true in urban areas. The same general pattern also holds for women. Here again this could be a sign of their motivation ("hard workers tend to be from the middle class"). But it could also be a rational response to the fact they earn higher wages, or simply a result of the fact that the poor are casually employed and as a result, occasionally they end up not finding anything to do.

Whatever the ultimate cause, a core driver of the differences between the poor and the middle class is that the middle class work longer hours, on more stable, higher-paying jobs, which 
they often had to go to some trouble to find. That, rather than their propensity to take risk and run businesses, seems to be at the core of their (relative) economic success.

\section{Investing in Human Capital}

\section{Family Size and Fertility}

The middle class lives in smaller families and has fewer children compared with the poor. One measure of this difference is that the share of the population that is under the age of 18 is smaller for the middle class than for the poor. Among the rural poor, the number of people under 18 as a ratio of the total family size ranges from 40 percent in Nicaragua to 62 percent in Panama. In urban areas, the range is similar, from 33 to 60 percent. This ratio falls substantially in all countries as incomes rise, although it remains high by the standards of high-income countries. The share of population under age 18 ranges between 16 and 54 percent for those in rural areas with daily per capita expenditures of $\$ 6-\$ 10$ and between 20 and 52 percent for that of the corresponding urban group.

These population ratios, by themselves, do not have to mean that the poor have more children; they could just have higher mortality in the older cohorts (as we will see later, this is also true). Unfortunately, the lack of consistent fertility histories in most Living Standard Measurement Surveys makes it hard to measure fertility directly. What we do see is that the number of children per adult woman in the household falls sharply as incomes rise. Among the extremely poor at below $\$ 1$ a day, there are between 1.8 (Ivory Coast) and 3.6 (Panama) children under age 13 per adult woman in the household. Everywhere except in Guatemala and Ivory Coast, the number drops by at least 0.5 when we move to the $\$ 2-\$ 4$ category. In Nicaragua, Pakistan, and Peru, the number of children actually drops by more than one. The number of children per family drops again by about the same amount when we go from the \$2-\$4 category to the $\$ 6-$ $\$ 10$ category. As a result, the rural families in the $\$ 6-\$ 10$ per day range have between 1 and 1.3 children per adult woman in all of our countries except Guatemala and Papua New Guinea.

It is possible that this difference partly reflects differences in taste-poor people do less to control fertility (which, in part, is what makes them poor). It could also be bad luck-people are poor because they had too many children. However, the most natural story probably has to do with incentives. As Gary Becker (1991) pointed out, perhaps the poor lack the financial or social resources to make those types of investments in their children that will really pay off financially: sending them to private school, paying for college education, and so on. Given that the poor know that they will not be able to make these investments, it perhaps makes economic sense for them to have many children and send them to work young. Either way, differences in fertility may be an important part of what allows the middle class to stay ahead of the poor.

\section{Education}

We already saw that while the rural middle class spends more or less the same fraction of income on education as the poor, the urban middle class often spends a substantially larger fraction. Therefore in both rural and urban areas, the middle class spends much more in absolute terms per child, especially since they have fewer children.

In part, this extra spending is explained by the fact that middle class families are more likely to send their children to school than the poor, as shown in Figure 8. Enrollment rates in the 712 age group both in urban and rural areas rise by a substantial amount in Ivory Coast, Pakistan, Udaipur, Nicaragua, Panama, Papua New Guinea, Tanzania, and East Timor when we move from the below $\$ 2$ category to the $\$ 6-\$ 10$ group. The increase is especially large (by a factor of two or more) for both boys and girls in Ivory Coast (urban and rural) and for girls in rural Pakistan. Elsewhere, there is either no change or a slow increase. 
Despite these increases, a substantial fraction of middle class children are not in primary school: In Tanzania, Papua New Guinea, Pakistan and Ivory Coast, the fraction of both boys and girls from families in the $\$ 2-\$ 4$ category going to primary school is less than 80 percent. This phenomenon is not due to isolated rural poverty; the lowest enrollment rate for this age group for middle class families (60 percent) is actually for girls in urban Ivory Coast.

Among the children above 13, the relationship between enrollment and economic well-being is, understandably, somewhat steeper. The share of children that age in school goes up by more than 50 percent between the $\$ 6$ to $\$ 10$ group and the extremely poor in a majority of countries and even triples in some (like Ivory Coast) though there are some places where it is flat or even goes down (like East Timor, Peru, and South Africa).

Even with these large increases in enrollment, if the expenditure per child in school remained the same, we would expect those between \$6 and \$10 to spend a smaller share on education than those below $\$ 1$, partly because the share of children going to school doesn't rise six-fold, and partly because the middle class has fewer children. In short, the middle class spends more, often much more, per child educated than the poor.

A part of this extra money can be accounted for by the fact that middle class children are more likely to remain in school after they are 18 , but a substantial part of it also goes to pay for private schools or tutoring outside school hours. In almost all countries, the share of children attending private school increases substantially with income both in rural and urban areas, although there is a lot of variation across countries. Another common phenomenon is tutoring after school. Kochar (2001) reports that, in India, the ratio of urban boys getting after-school tutoring was about 20 percent for primary age children and close to 40 percent for the secondary age groups. The idea of someone below the U.S. poverty line paying for private schooling for their children might seem bizarre to people who have in mind the image of private schools in high-income countries, but that analogy would be misleading. Private schools in developing countries are often very cheap (in South Asia, it is not uncommon for them to cost less than $\$ 150$ per year) and largely unregulated, and the quality is correspondingly mediocre or worse. There used to be a large billboard on the outskirts of the city of Udaipur cheerfully advertising a new Engleesh Medium School.

The fact that the people are not sending their children to the free public schools, even for the early grades, reveals something about the quality of those public schools. Indeed, looking at teacher absence rates in villages in India, Kremer, Chaudhury, Rogers, Muralidharan, and Hammer (2005) show that private schools spring up in areas where the public schools are particularly bad, and the private school teachers in those communities are much less likely to be absent than the public school teachers, even though they are often paid a fraction of what public school teachers make.

The switch towards private schools and tutoring could also explain why the phenomenon of increasing educational spending is primarily an urban phenomenon. As a greater share of highincome people live in urban areas and the population is more geographically concentrated, it is natural that there would be a greater supply of more expensive options for education in urban areas. In addition, households living with daily per capita expenditures between $\$ 6$ and $\$ 10$ in urban areas are more likely to live among even higher-income people who set the norms for the education that they want for their children. Yet another possibility is that households in urban areas are more often migrants, who may therefore be especially ambitious for themselves and their children. Finally, the returns to education may be larger in urban areas. 


\section{Health Care}

The likelihood that individuals will see a health provider when they are sick goes up sharply with daily per capita expenditures in both rural and urban areas. The increase seems to be steeper in rural areas. The middle class also consumes more expensive health care. With this combination of higher quantity and higher price, health care spending as a share of daily per capita expenditures rises quite sharply in most countries; for example, in urban Mexico it goes from 1.6 percent for the extremely poor to 4.4 percent for those with daily per capita expenditures between $\$ 6$ and $\$ 10$, in urban Indonesia from 1.4 to 3.4 percent, and in Hyderabad from 5 to 17 percent in the same categories. In part, this pattern reflects a shift towards private health care for the middle class. However, this cannot be the whole story, since in some countries (like India and Pakistan), even the poorest in our sample say that they go to private doctors, while in others (Mexico) everyone says that they use the public health system. In these countries, the middle class are presumably going to more expensive private doctors when they go and perhaps paying more to public doctors to jump the queue; the doctors they see are more competent and exert more effort. (Das and Hammer (2007) find this pattern among the slumdwellers of Delhi.) In addition, the middle class probably buy more of the medicines suggested by the doctors, get more tests done, go for the recommended surgeries, and deliver children in hospitals rather than at home.

\section{Investment or Consumption?}

The middle class lives distinctly healthier lives than the poor. They go to the doctor more often and spend more per visit. As we saw earlier, they are also much more likely to have access to running water, latrines, and electricity. As far as children's education is concerned, they spend much more per child, partly in more years of schooling and partly in better quality.

Economists are used to thinking of health and education choices as investment decisions, but it is possible that much of this extra spending on health and education by the middle class should be seen as consumption. Even though spacious houses and latrines contribute to cleaner environments and better health, and tap water is safer to drink, are these amenities mainly for comfort, or do they lead to better health outcomes? Does the more expensive doctor give the middle class better treatment, or is the doctor just pandering to their hypochondria? Is it actually true that the extra expenditure in health and education pays off in terms of a healthier life or a higher income?

In Banerjee and Duflo (2007a), we ask whether there is a payoff in terms of the starkest possible outcome-mortality. We observed that middle class adults are more likely than the poor to report that their parents are alive, which suggests lower mortality among those 50 and above. We then used panel data from the two countries-Indonesia and Vietnam-where we have detailed consumption data and where the households were interviewed twice with about five years between the two interviews. We use this data to answer a simple question: Are those who were poor in a particular survey year less likely to survive until the next survey year compared to those in the middle class?

The answer turns out to be surprisingly clear-cut. Among those who were 50 years or older in the base year, the poor are much more likely to die than the middle class. In Indonesia, for example, about 15 percent of those who were poor and aged 50 and above in 1993 had died by 1997 . The corresponding number for those with expenditures of $\$ 6-\$ 10$ was 7 percent. The difference is particularly striking in rural areas (15 versus 3 percent) but substantial also in urban areas (18 versus 11 percent). The patterns are similar in Vietnam.

Of course, the direction and channels of causality here are unclear. Perhaps people become poor because they are sick. Or perhaps poor health is in part inherited, so that less healthy old 
people live with low-income and less healthy younger adults. But on balance, it seems plausible that the richer households live substantially longer in part because they live healthier lives. An interrelated combination of their economic life, their life decisions, and their investments in home life - better sanitation, water on tap, a latrine, less strenuous physical labor, better doctors, fewer childbirths, better nutrition-not only allow the middle class to live more comfortable lives or to show off their wealth: they also allow them to live longer.

\section{What is Middle Class about the Middle Classes?}

Nothing seems more middle class than the fact of having a steady well-paying job. While there are many petty entrepreneurs among the middle class, most of them do not seem to be capitalists in waiting. They run businesses, but for the most part only because they are still relatively poor and every little bit helps. If they could only find the right salaried job, they might be quite content to shut their business down. If the middle class matters for growth, it is probably not because of its entrepreneurial spirit.

The middle class also have fewer children and spend much more on the education and health of these children as well as on their own health. It is interesting to speculate whether this has something to do with the kind of jobs they have. Perhaps the sense of control over the future that one gets from knowing that there will be an income coming in every month-and not just the income itself-is what allows the middle class to focus on building their own careers and those of their children.

The reason why this matters-indeed why it might matter a lot—is that it leads us to the idea of a "good job." A good job is a steady, well-paid job—a job that allows one the mental space needed to do all those things the middle class does well. This is an idea that economists have often resisted, on the grounds that good jobs may be expensive jobs, and expensive jobs might mean fewer jobs. But if good jobs mean that children grow up in an environment where they are able to make the most of their talents, one might start to think that it may all be worth it.

\section{Acknowledgements}

We are once again indebted to Andrei Shleifer for encouraging us to write this essay and to the editors of the Journal of Economic Perspectives for detailed comments. We thank Tricia Gonwa, Remi Jedwab, and Stefana Stancheva for outstanding research assistance, and Pascaline Dupas for her comments.

\section{References}

Acemoglu, Daron; Zilibotti, Fabrizio. Was Prometheus Unbound by Chance? Journal of Political Economy 1997;105(4):709-51.

Banerjee, Abhijit; Duflo, Esther; Glennerster, Rachel. A Snapshot of Micro Enterprises in Hyderabad. MIT; 2006. Unpublished paper

Banerjee, Abhijit; Duflo, Esther. Growth Theory through the Lens of Development Economics. In: Durlauf, Steve; Aghion, Philippe, editors. Handbook of Economic Growth, 1A. Elsevier Science; North Holland: 2005. p. 473-552.

Banerjee, Abhijit; Duflo, Esther. Aging and Death under a Dollar a Day. National Bureau of Economic Research Working Paper W13683. 2007a

Banerjee, Abhijit; Duflo, Esther. The Economic Lives of the Poor. Journal of Economic Perspectives 2007b;21(1):141-67.

Birdsall, Nancy; Graham, Carol; Pettinato, Stefano. Stuck in The Tunnel: Is Globalization Muddling The Middle Class? Brookings Institution, Center on Social and Economic Dynamics WP No. 14. 2000

Becker, Gary. A Treatise on the Family. Harvard University Press; 1991.

Besley, Timothy; Burgess, Robin. Can Labor Regulation Hinder Economic Performance? Evidence from India. The Quarterly Journal of Economics 2004;119(1):91-134. 
Boot HM. Real Incomes of the British Middle Class, 1760-1850: The Experience of Clerks at the East India Company. The Economic History Review 1999;52(4):638-68.

Das, Jishnu; Hammer, Jeffrey. Money for Nothing: The Dire Straits of Medical Practice in Delhi, India. Journal of Development Economics 2007;83(1):1-36.

Deaton, Angus. The Analysis of Household Surveys: A Microeconomic Approach to Development Policy. John Hopkins University Press; 1997.

De Mel, Suresh; McKenzie, David; Woodruff, Christopher. Returns to Capital in Microenterprises: Evidence from a Field Experiment. World Bank Policy Research Working Paper 4230. 2007a

De Mel, Suresh; McKenzie, David; Woodruff, Christopher. Who Does Microfinance Fail to Reach? Experimental Evidence on Gender and Microenterprise Returns. BREAD Working Paper No. 157. 2007b. http://www.cid.harvard.edu/bread/abstracts/157.htm

Doepke M, Zilibotti F. Social Class and the Spirit of Capitalism. Journal of the European Economic Association 2005;3(2-3):516-24.

Doepke, M.; Zilibotti, F. Occupational Choice and the Spirit of Capitalism. Institute for the Study of Labor, (IZA); Bonn, Germany: 2007. IZA Discussion Paper No. 2949

Easterly, William. The Middle Class Consensus and Economic Development. Journal of Economic Growth 2001;6(4):317-35.

Engel, Ernst. Die Lebenskosten Belgischer Arbeiter-Familien Fruher and jetzt. International Statistical Institute Bulletin 1895;9:1-74.

Foster, Andrew; Mark, Rosenzweig. Agricultural Development, Industrialization, and Rural Inequality. 2004. http://ipc.umich.edu/edts/pdfs/AgDev.pdf

Foster, Andrew; Mark, Rosenzweig; Forthcoming. Economic Development and the Decline of Agricultural Employment. In: Schultz, T.; Strauss, John, editors. Handbook of Development Economics, 4. North-Holland:

Frederick, Jim. Thriving in the Middle Kingdom. TIME Magazine, November 11. 2002

Glewwe, P.; Grosh, M. Designing Household Survey Questionnaires for Developing Countries: Lesson from 10 Years of LSMS Experience. World Bank; Washington DC: 1999.

Kochar, Anjini. Emerging Challenges for Indian Education Policy. Center for Research on Economic Development and Policy Reform Working Paper 97. 2001

Kremer, Michael; Chaudhury, Nazmul; Rogers, F. Halsey; Muralidharan, Karthik; Hammer, Jeffrey. Teacher Absence in India: A Snapshot. Journal of the European Economic Association 2005;3(23):658-67.

Kremer, Michael; Chaudhury, Nazmul; Hammer, Jeffrey; Rogers, F. Halsey; Murailadharan, Karthik. Missing in Action: Teacher and Health Worker Absence in Developing Countries. Journal of Economic Perspectives 2006;20(1):91-116. [PubMed: 17162836]

Landes, David. The Wealth and Poverty of Nations. Norton; New York: 1998.

Murphy, Kevin M.; Schleifer, Andrei; Vishny, Robert. Industrialization and the Big Push. Journal of Political Economy 1989;97(5):1003-1026.

Officer, Lawrence. Purchasing Power of the British Pound from 1264 to 2006. 2007. MeasuringWorth.com. http://www.measuringworth.com/ppoweruk/

Rubalcava, L.; Teruel, G. User's Guide to the Mexican Family Life Survey. Universidad Iberoamericana; 2004. Unpublished paper

Weber, Max. The Protestant Ethic and the Spirit of Capitalism. Germany: 1905. 


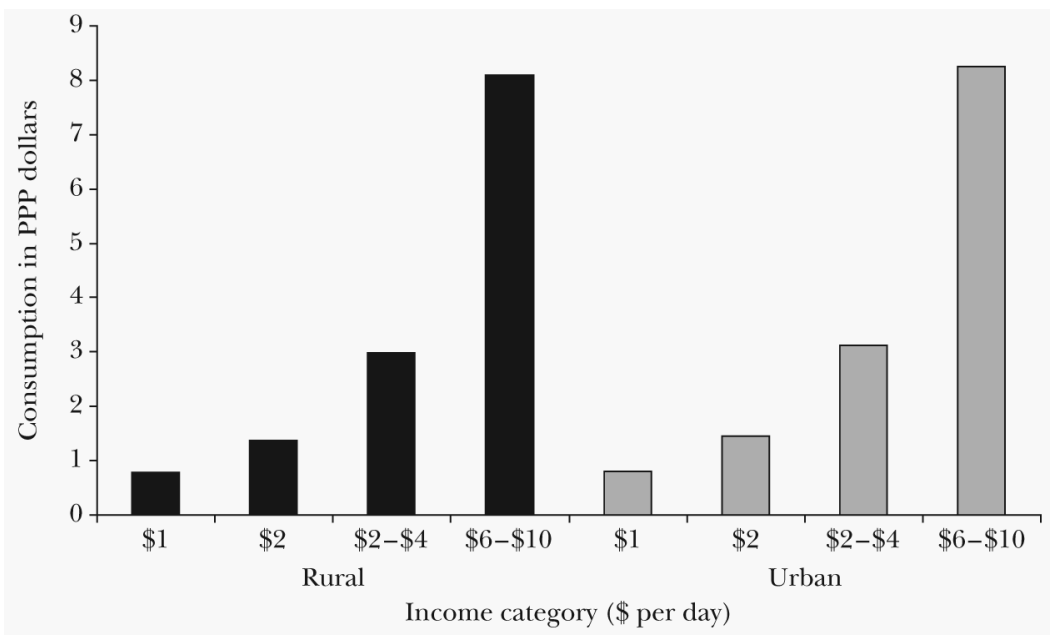

Figure 1.

Average Daily Consumption per Capita 


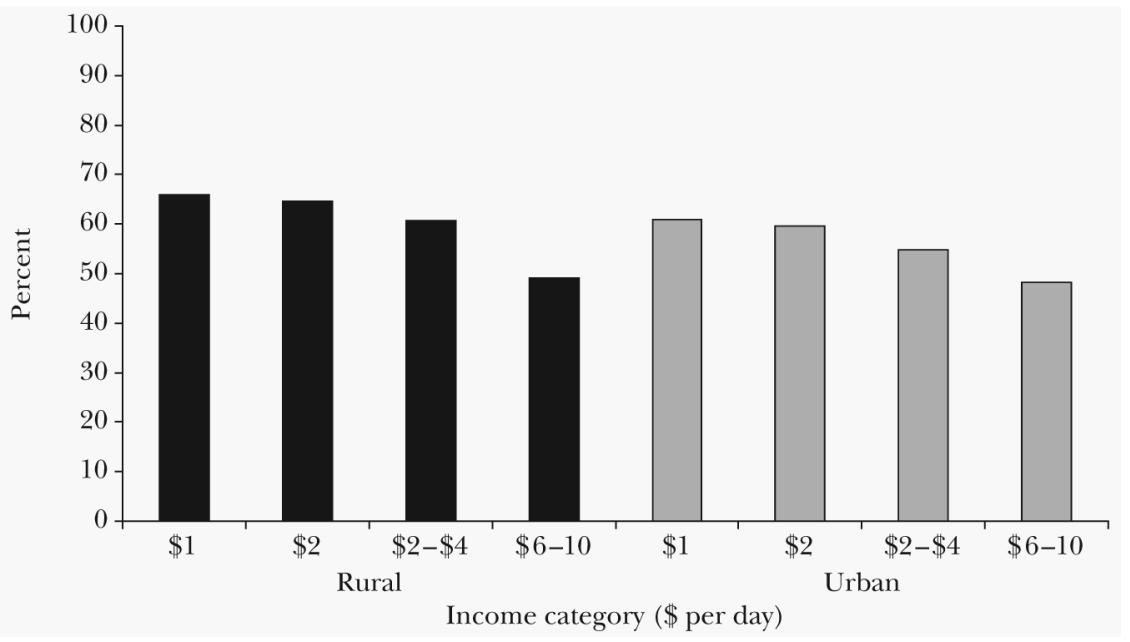

Figure 2.

Percentage of Household Budget Spent on Food 


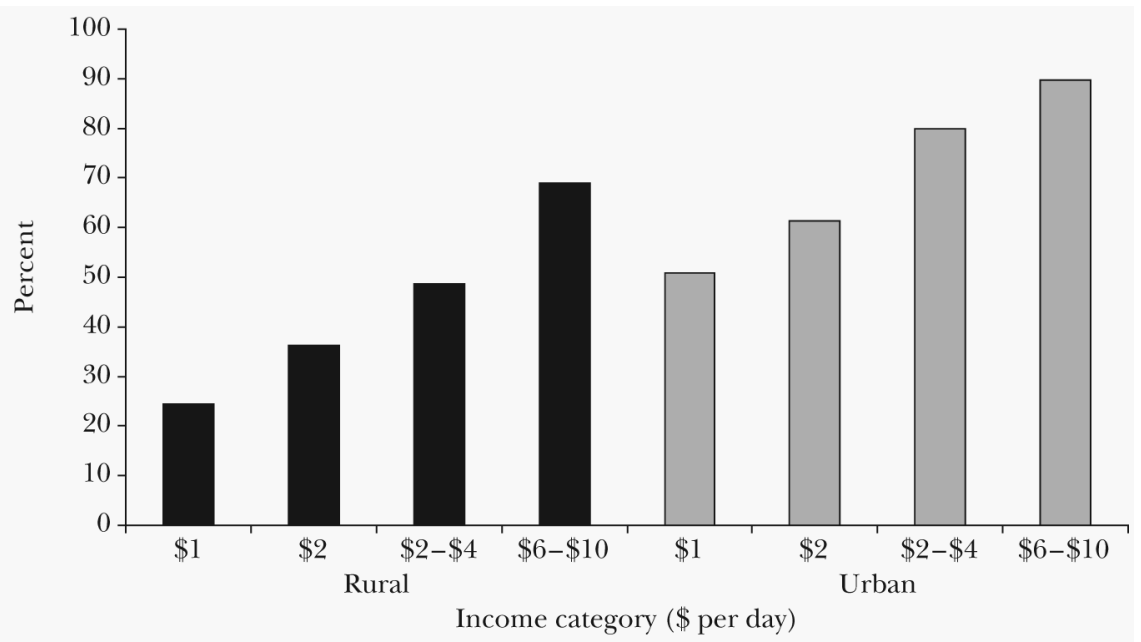

Figure 3.

Percent of People Living in a Household with a TV 


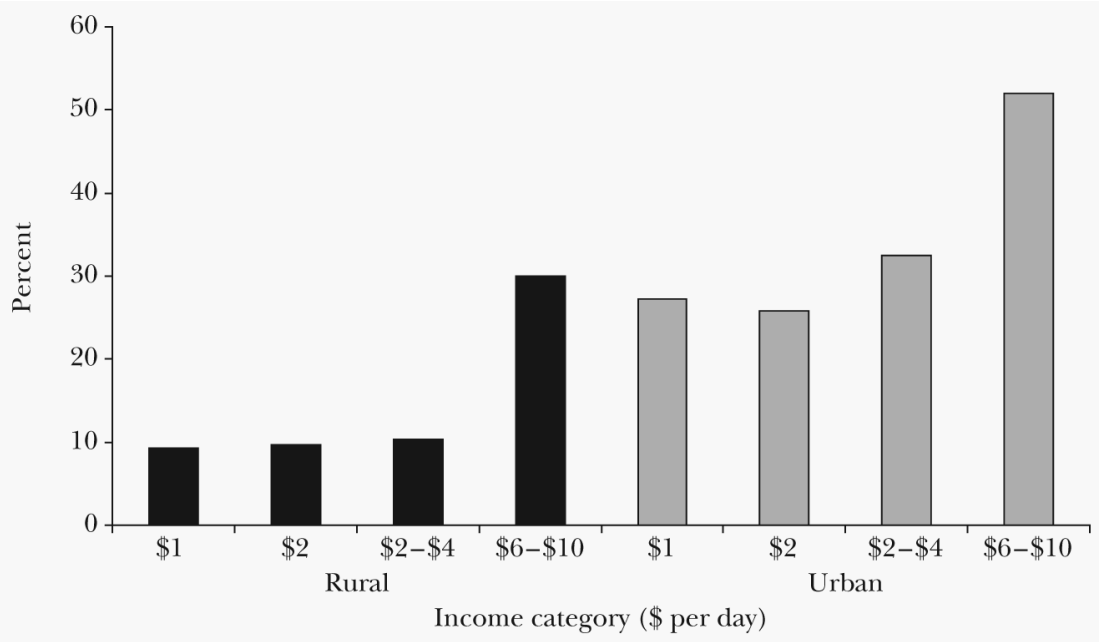

Figure 4.

Percent of People with Access to Tap Water 


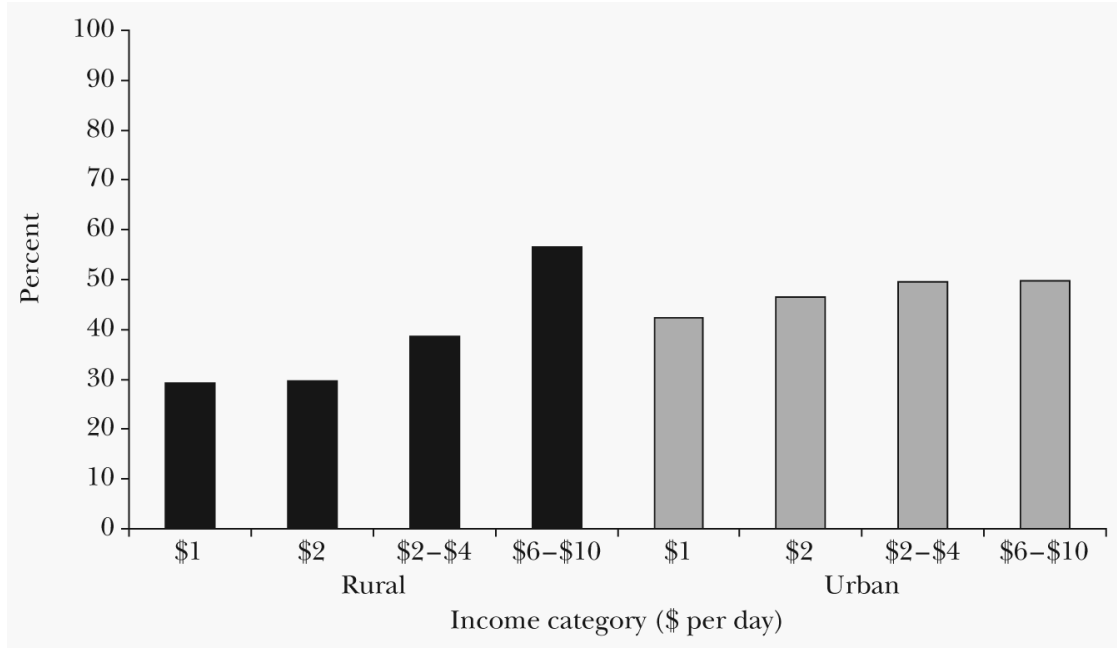

Figure 5.

Percent of Households with Nonagricultural Businesses 


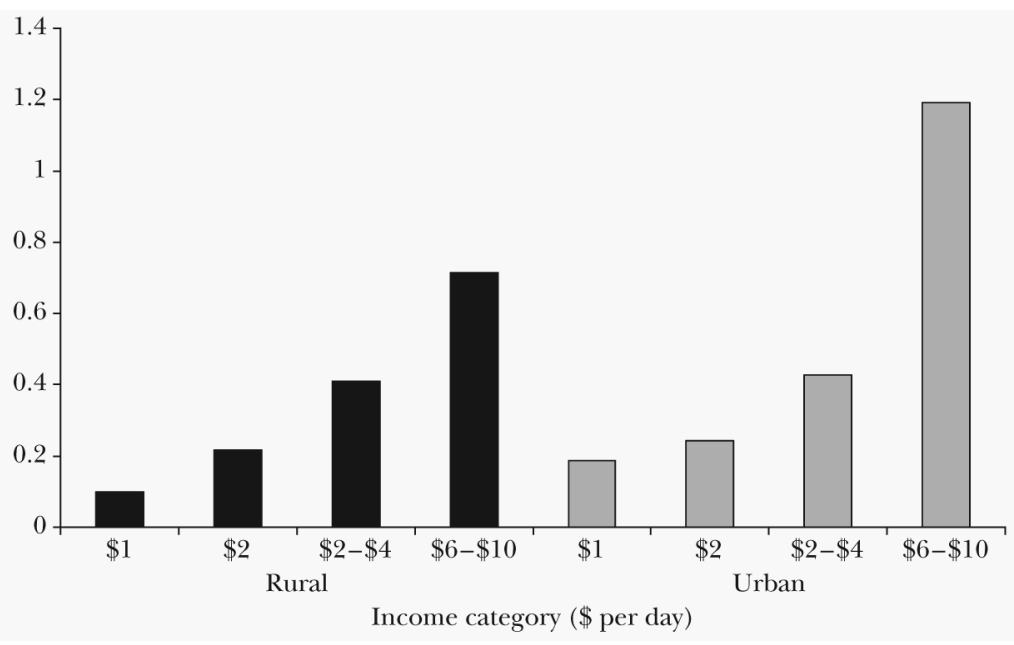

Figure 6.

Average Number of Paid Non-family Workers per Business 


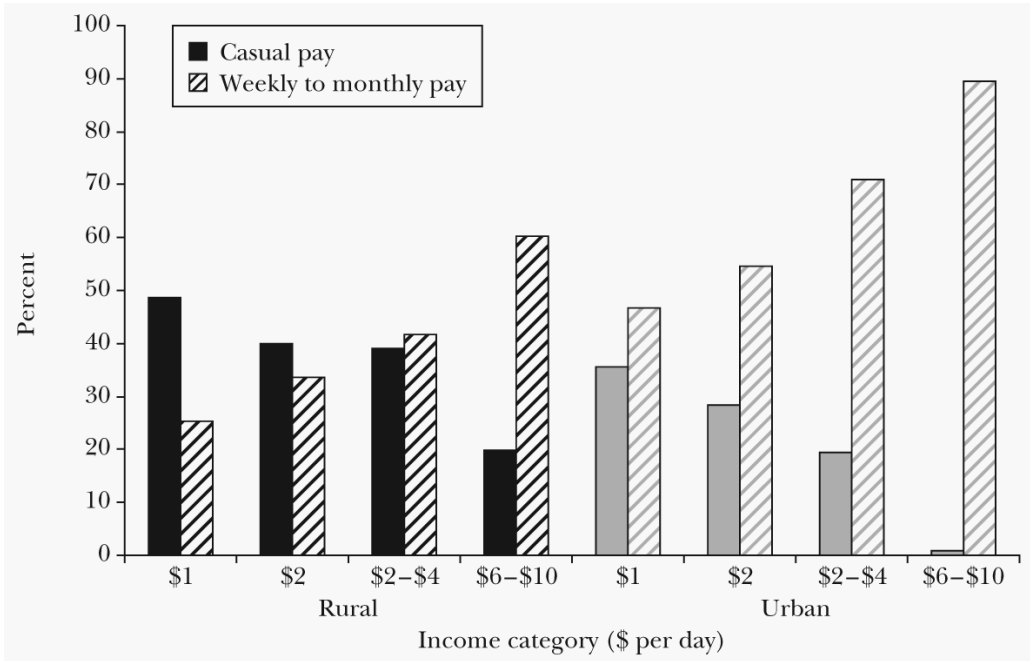

Figure 7.

Percentage of Employed People Receiving Casual or Weekly to Monthly Payment 


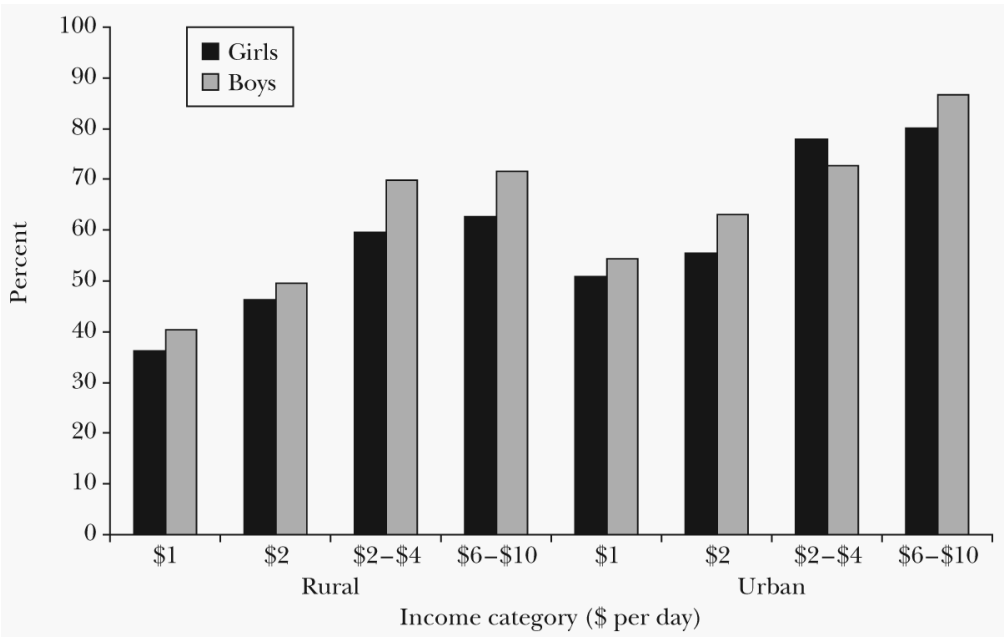

Figure 8.

Percentage of Children Aged 13 to 18 in School 


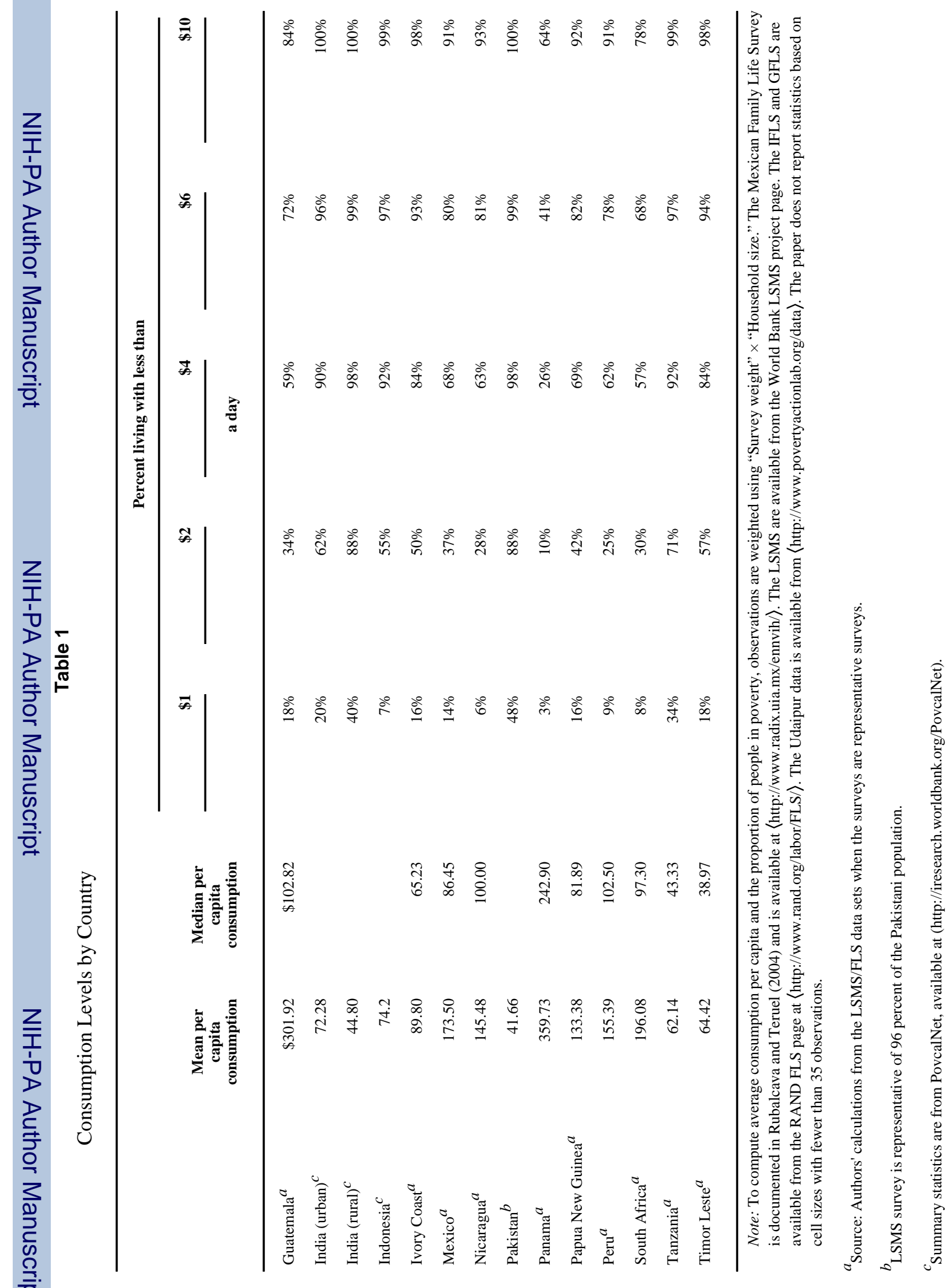


Table 2

Inventory of a General Store in a Village in Rural Karnataka, India

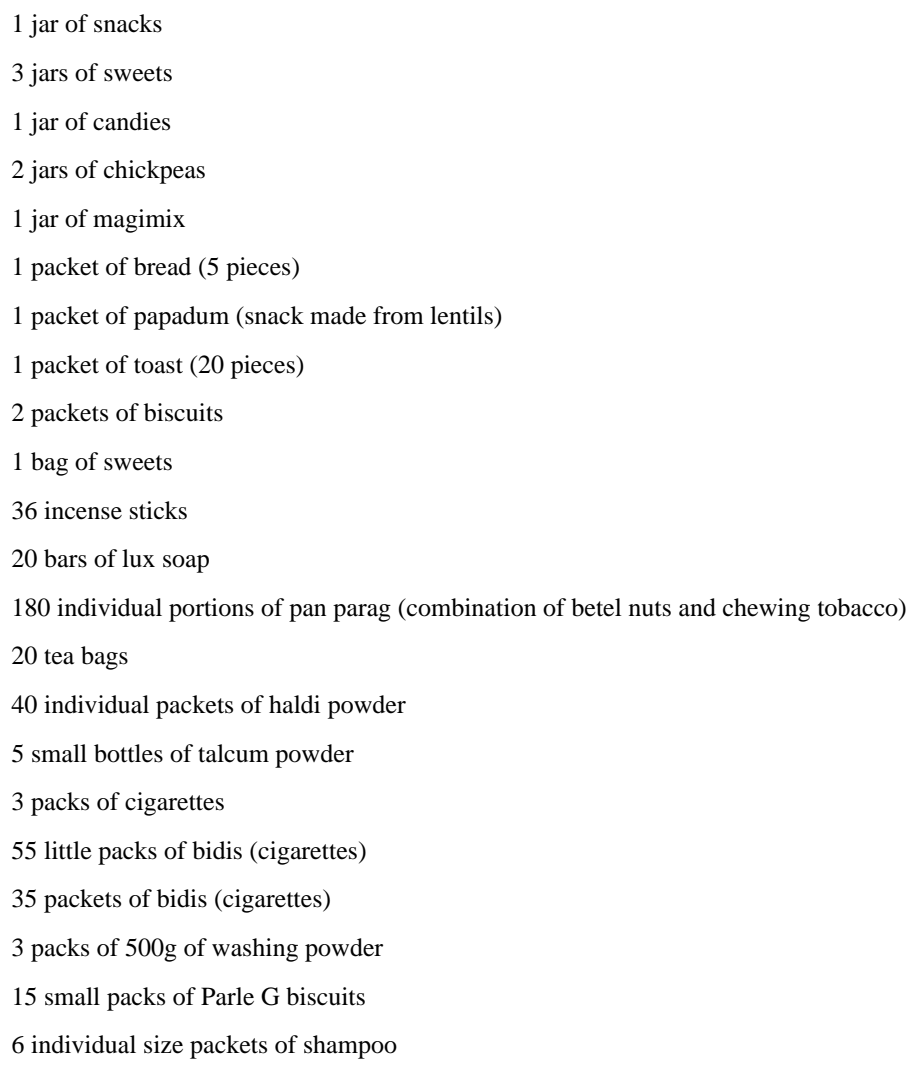




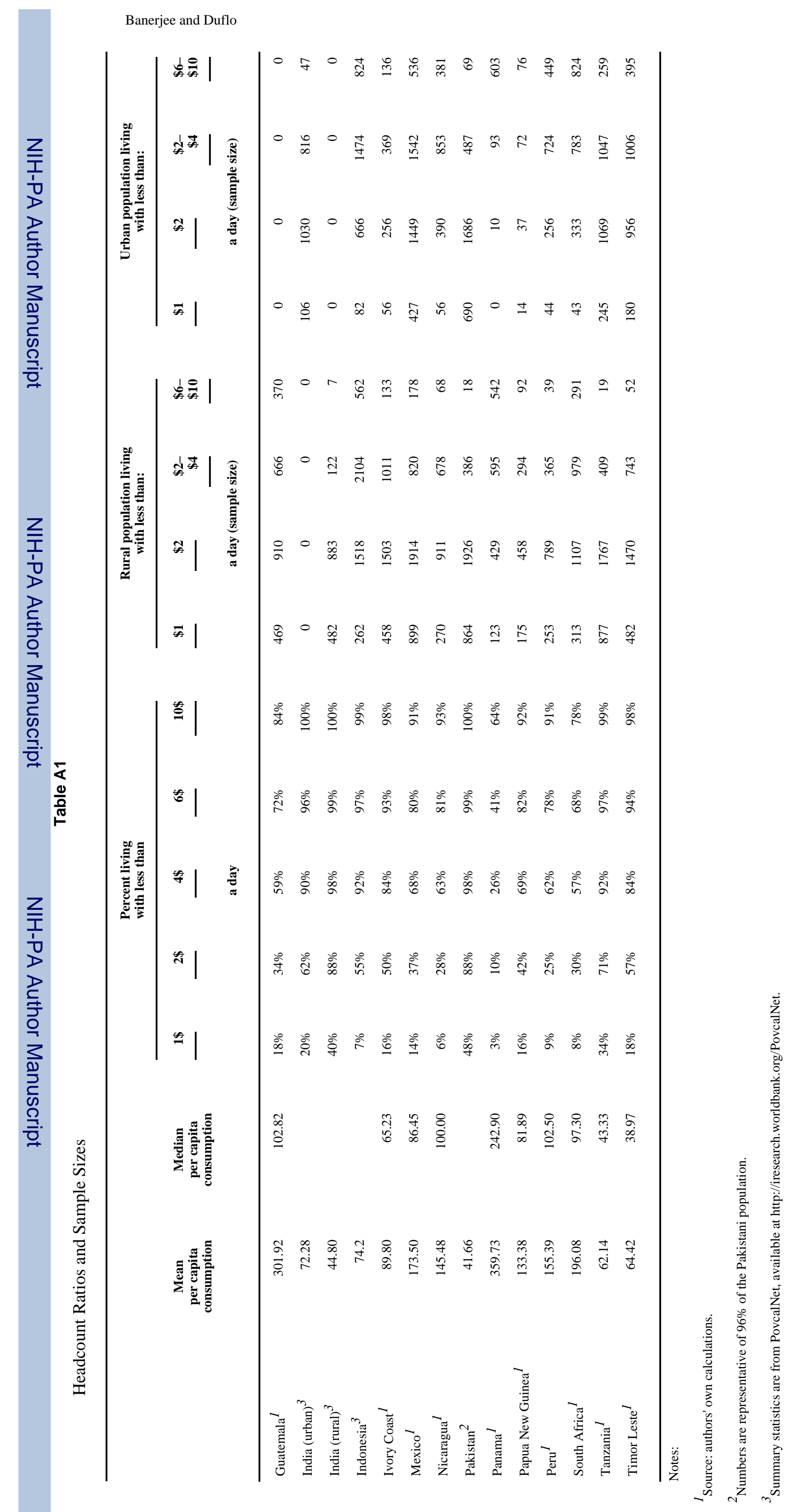




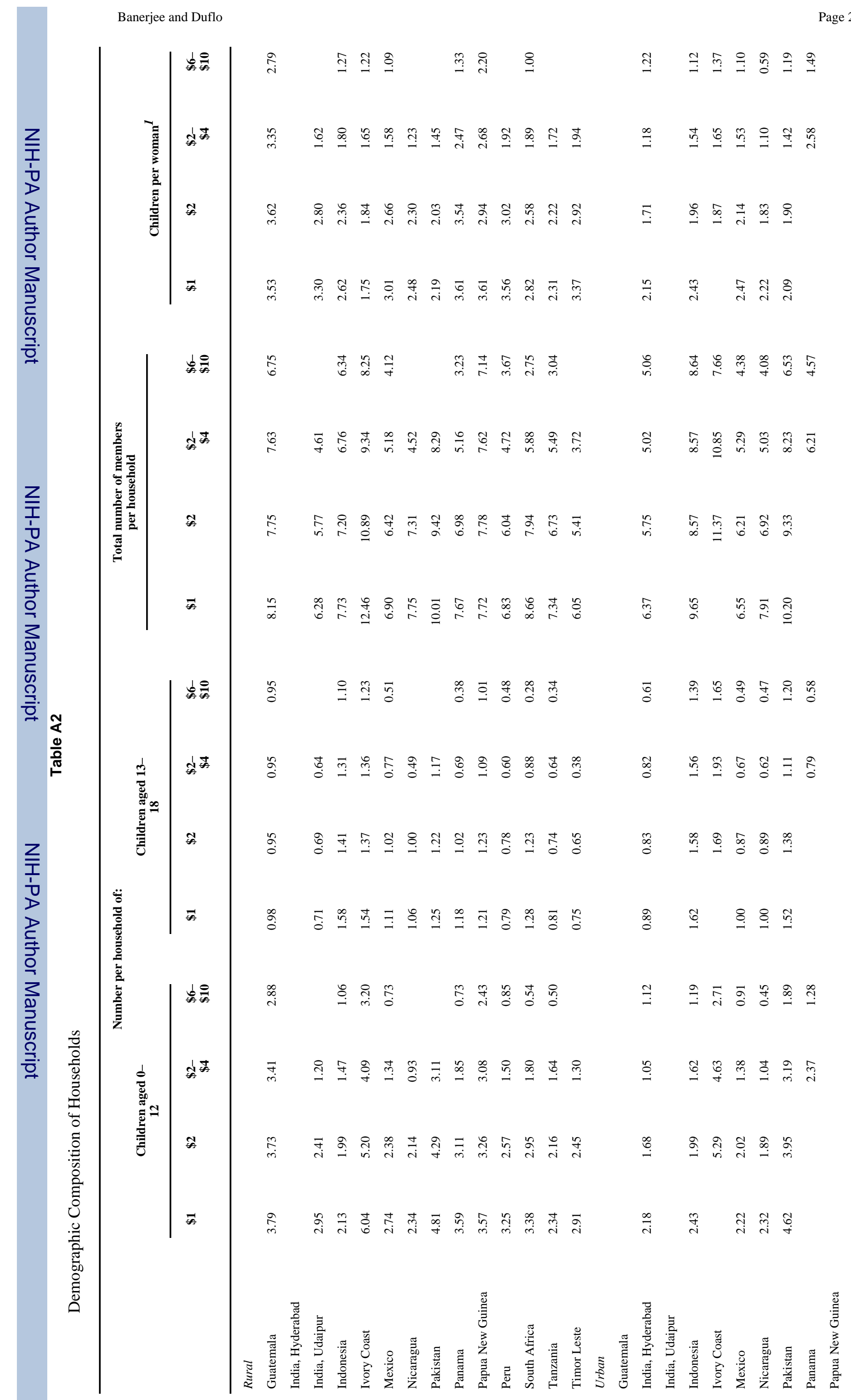




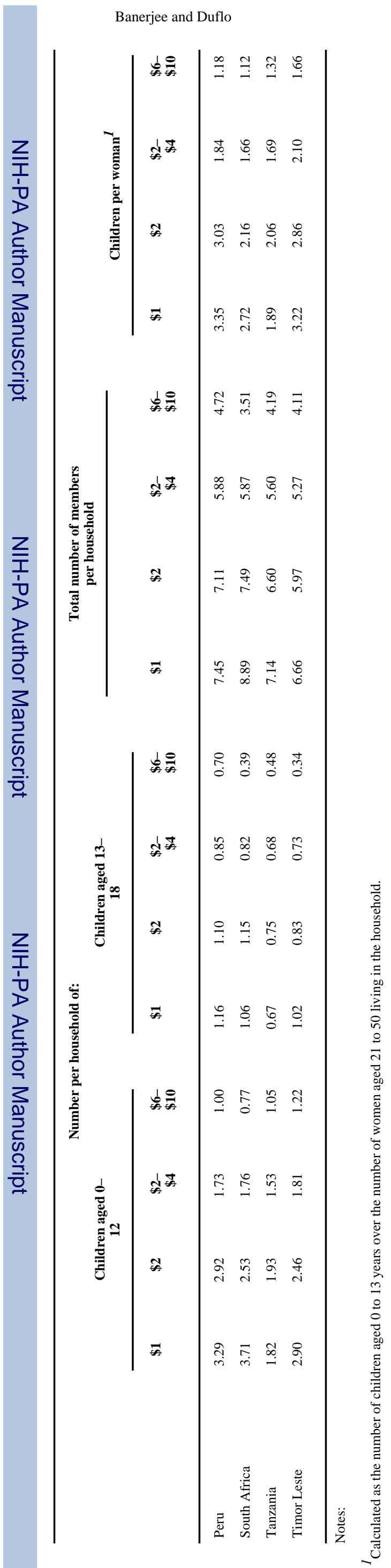

Page 30 


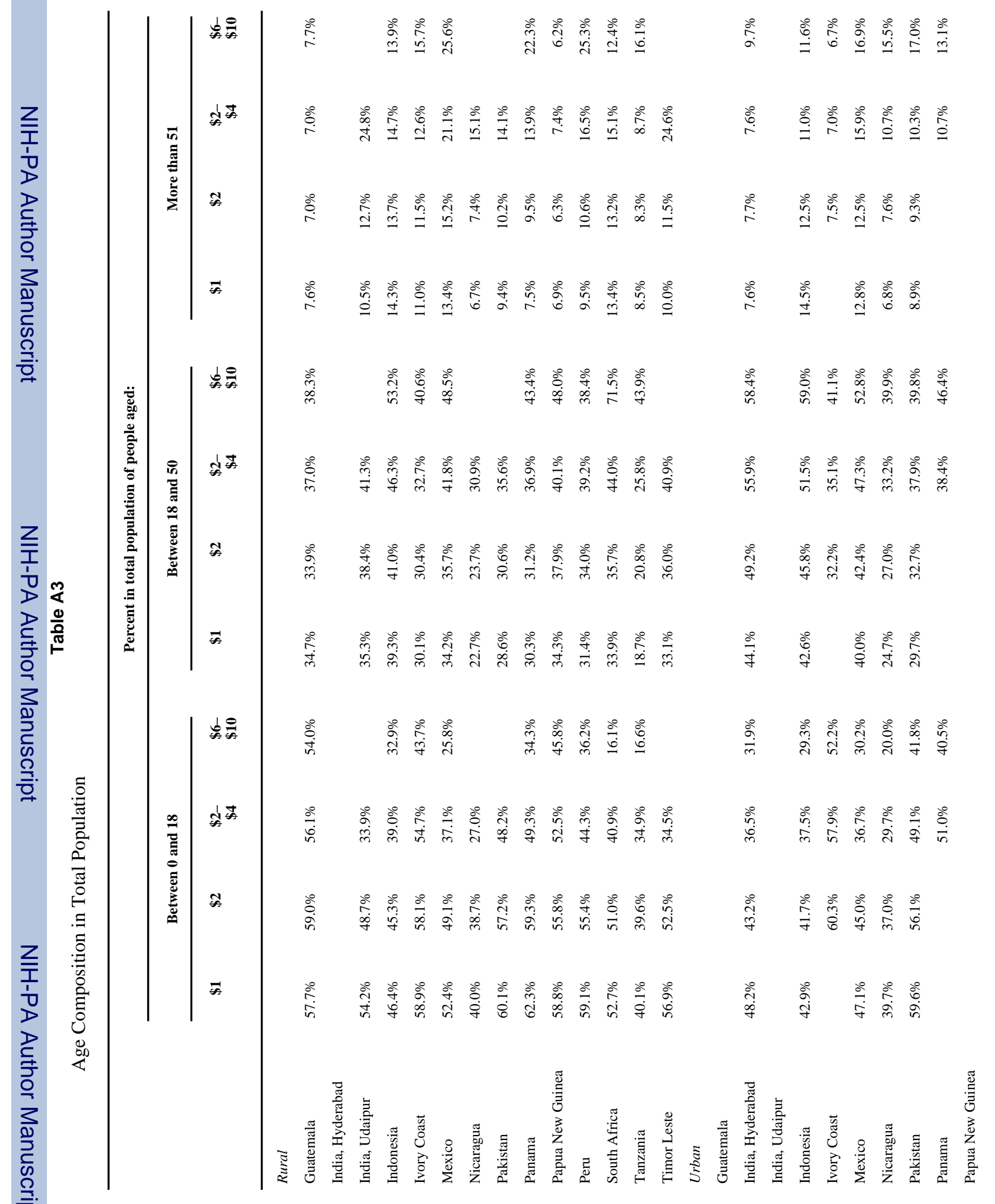




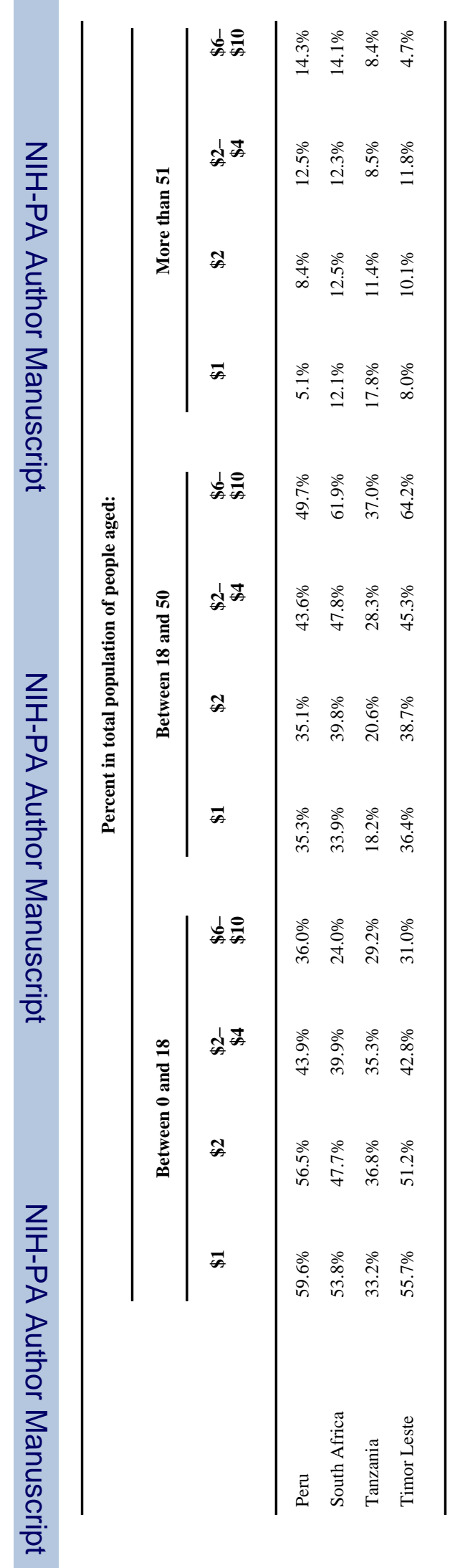




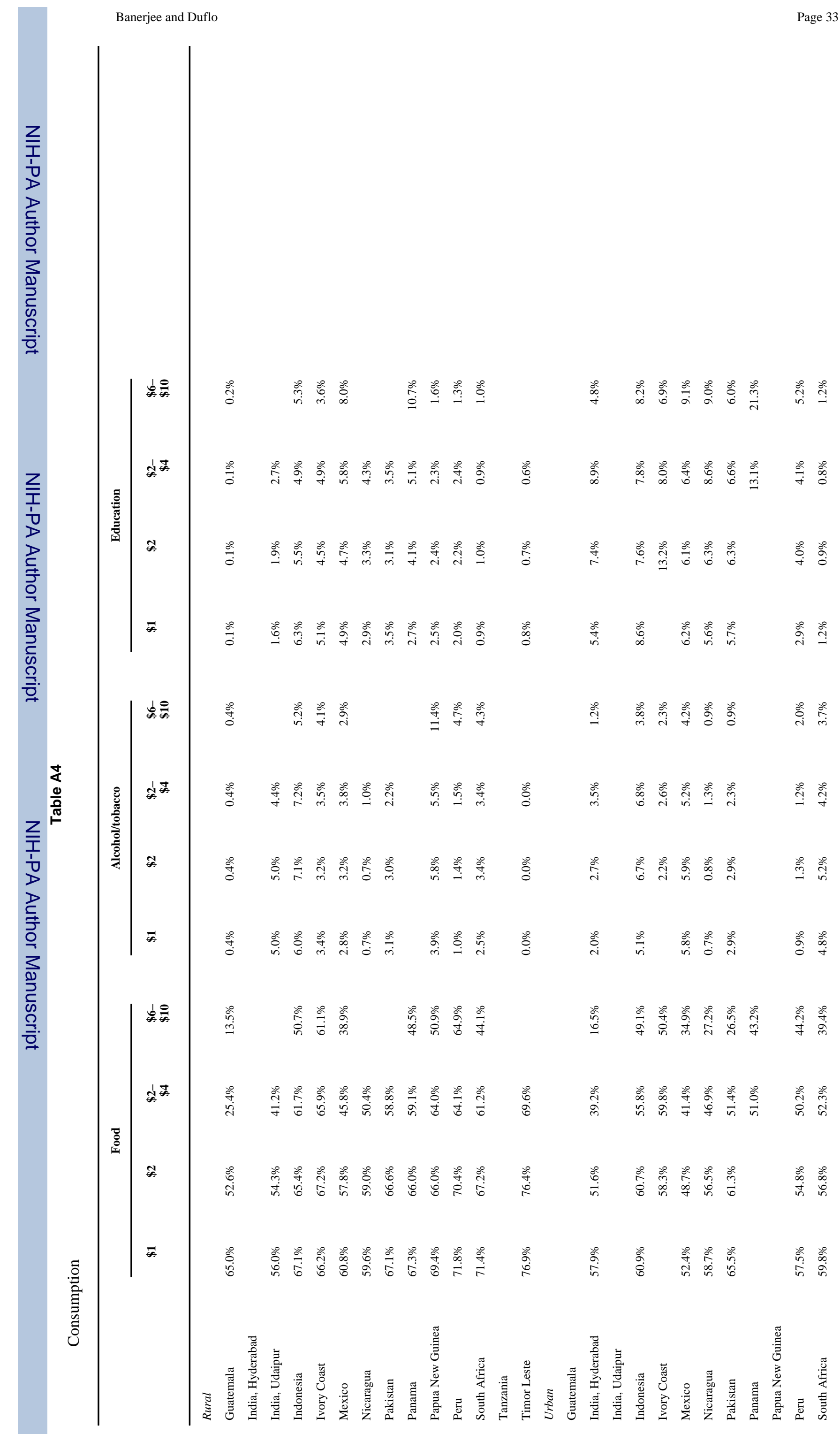




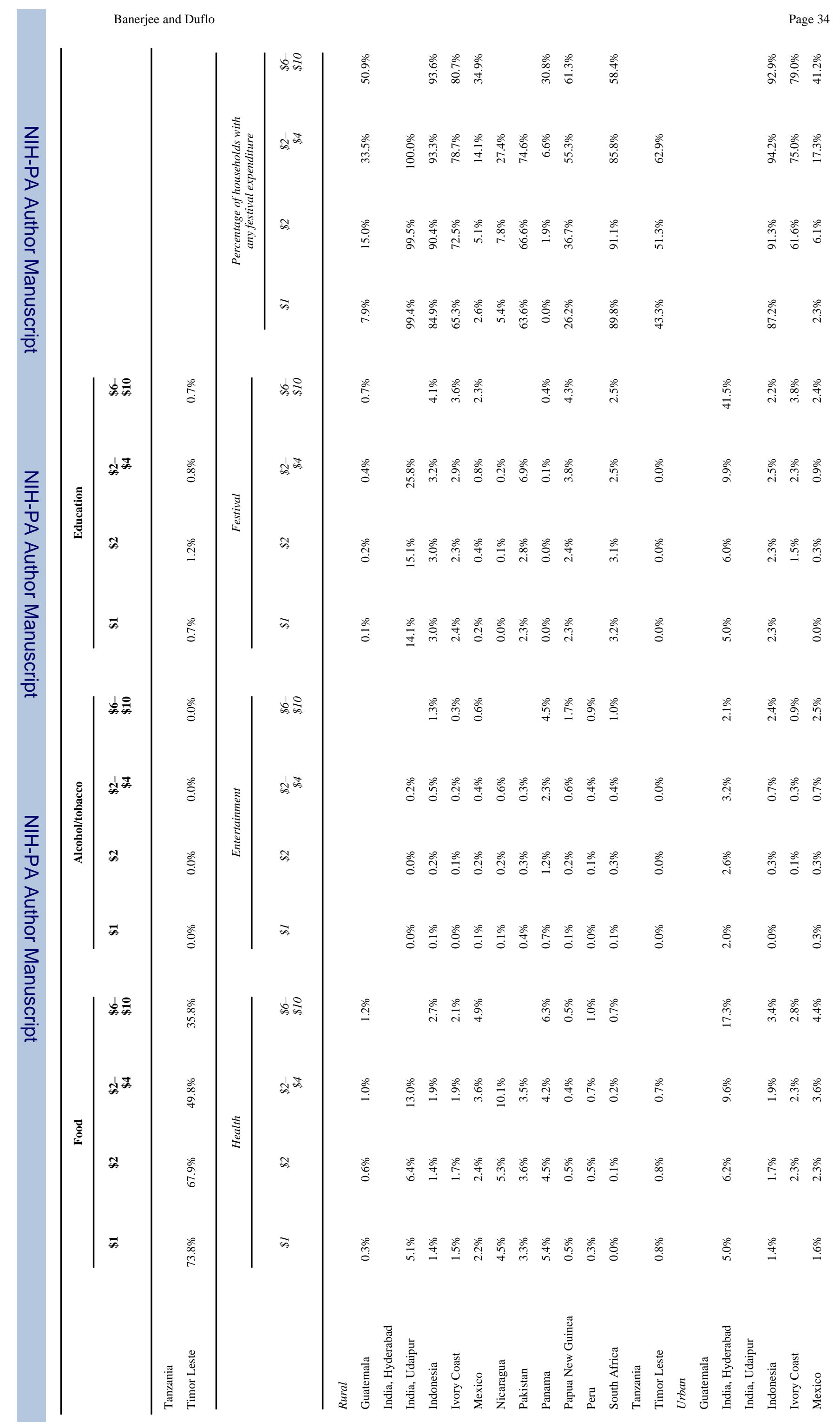




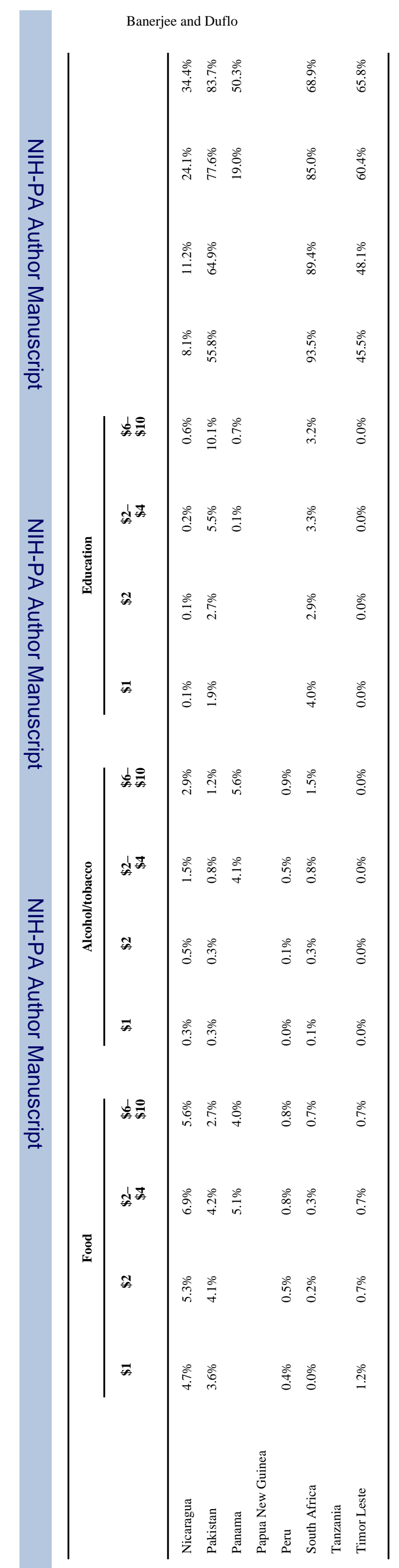

Page 35 


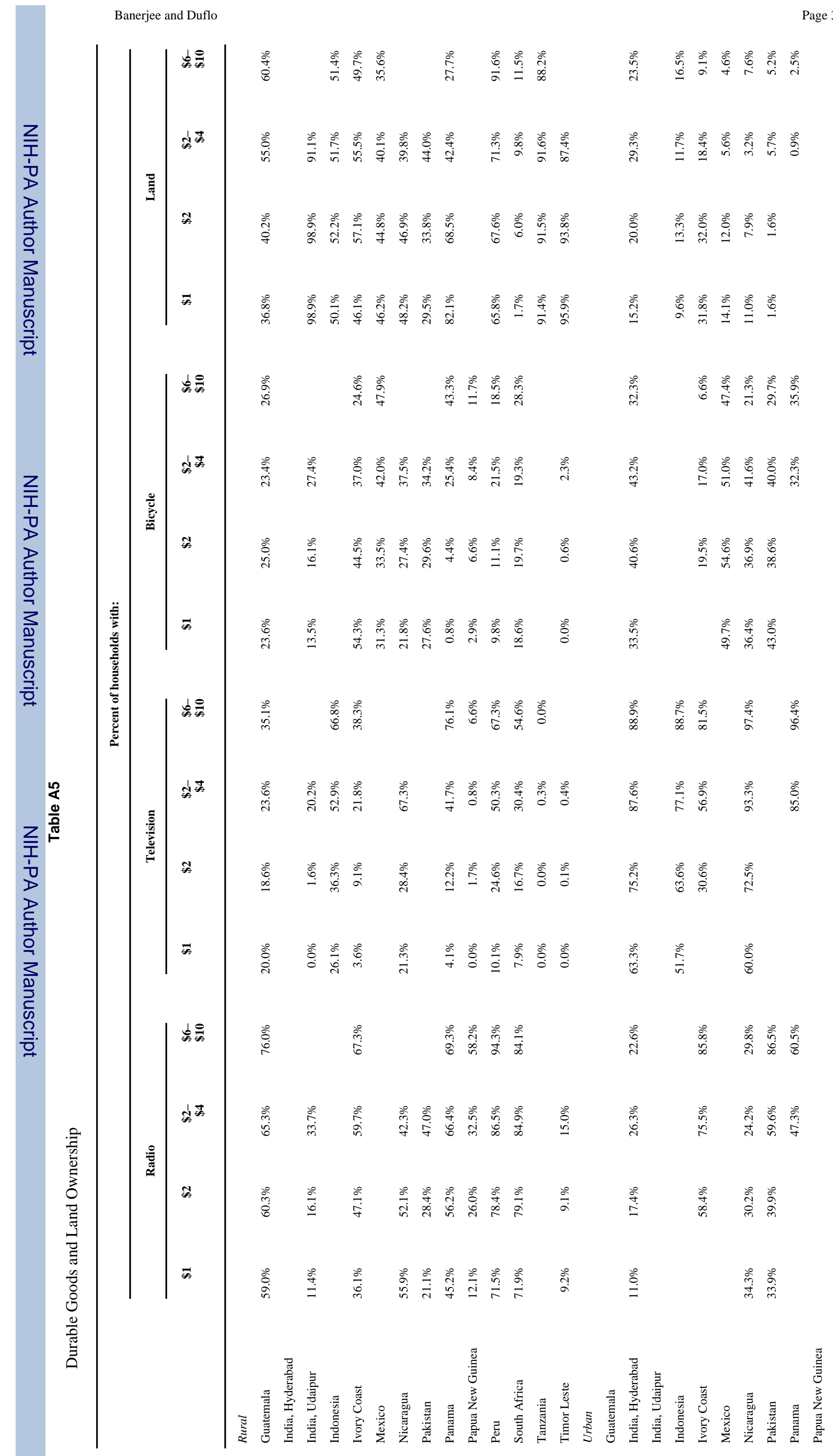




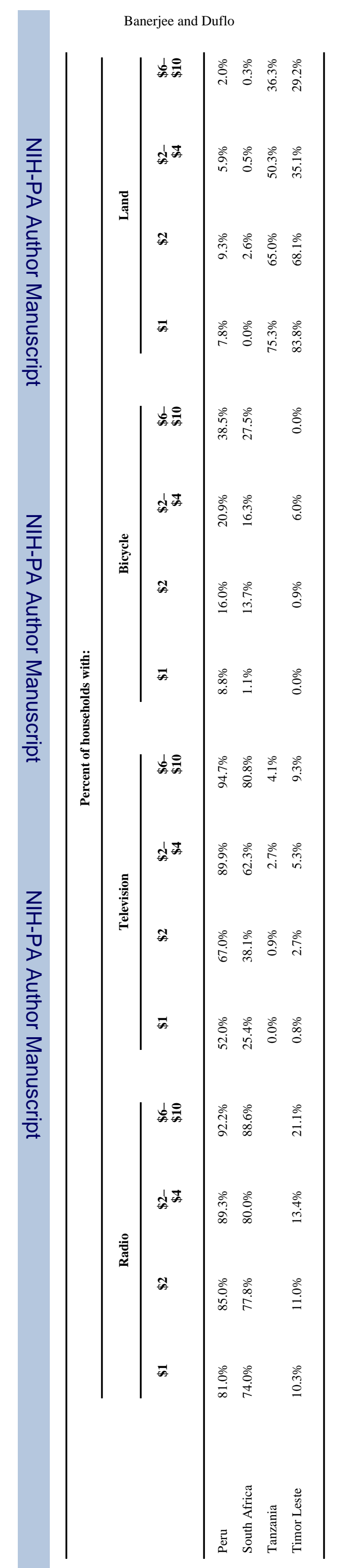

Page 37 


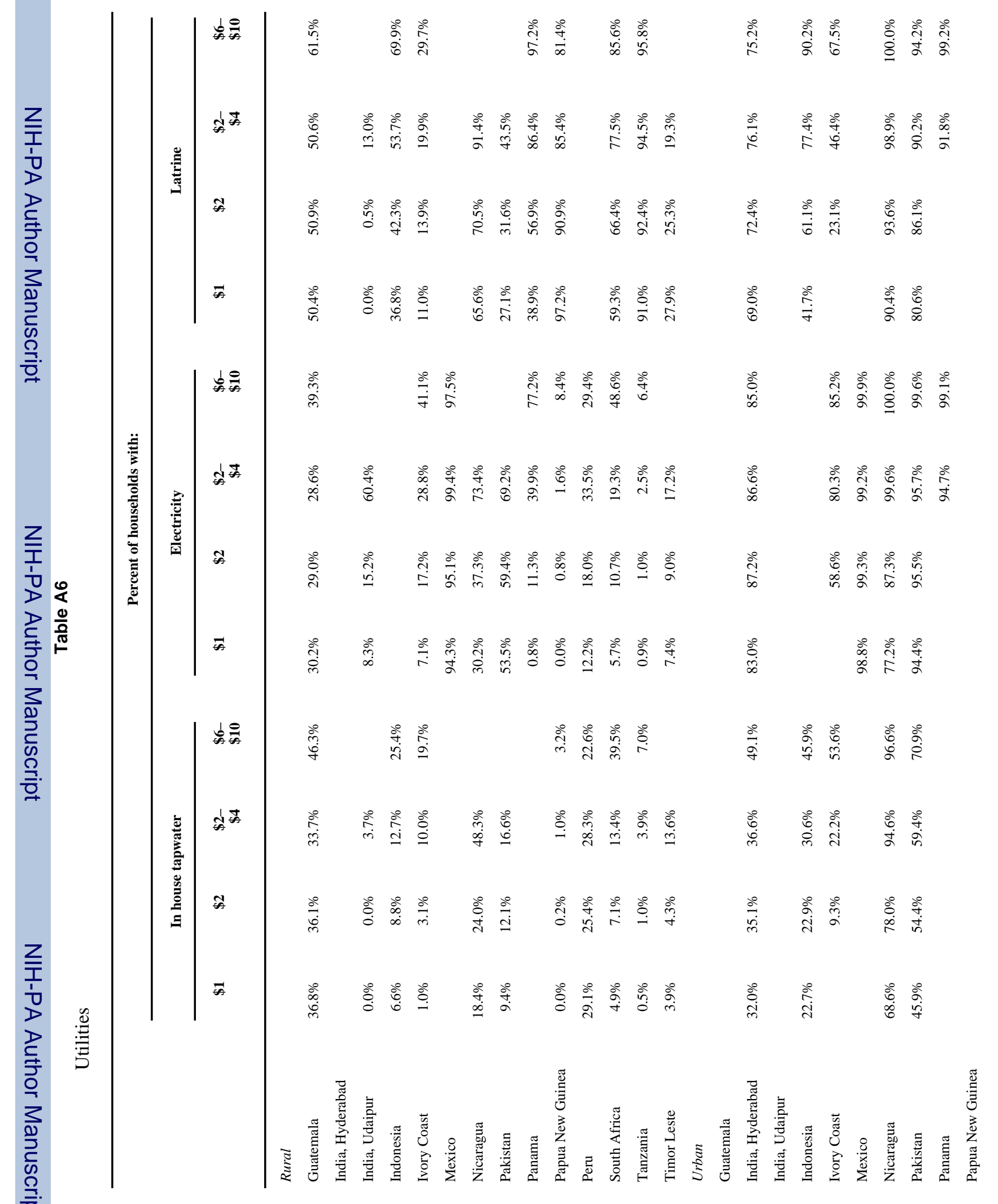




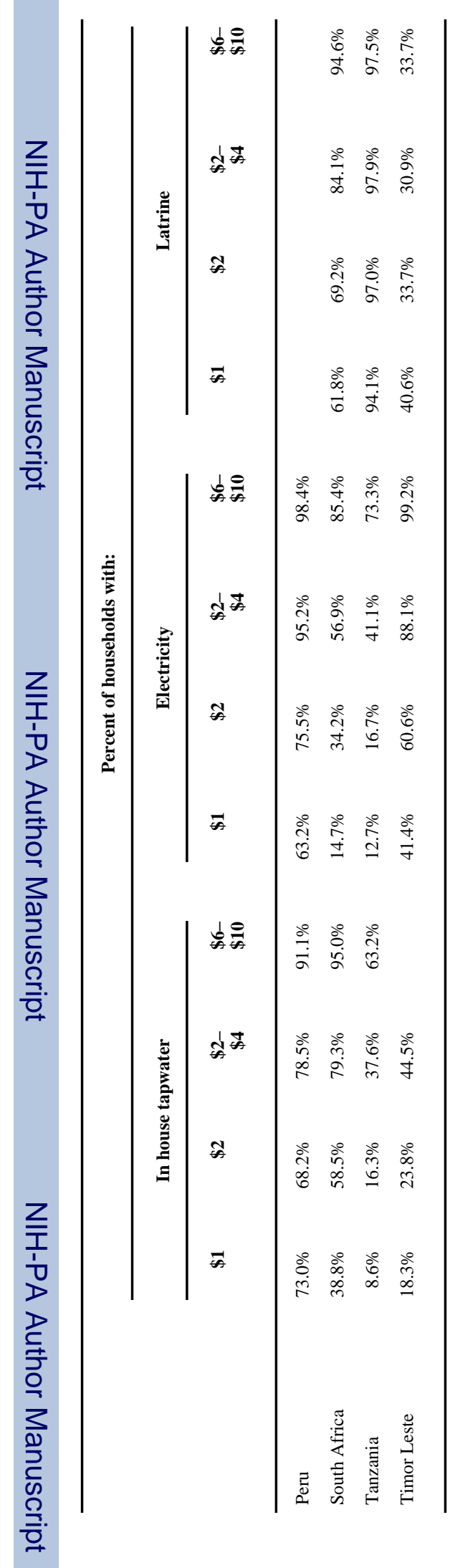




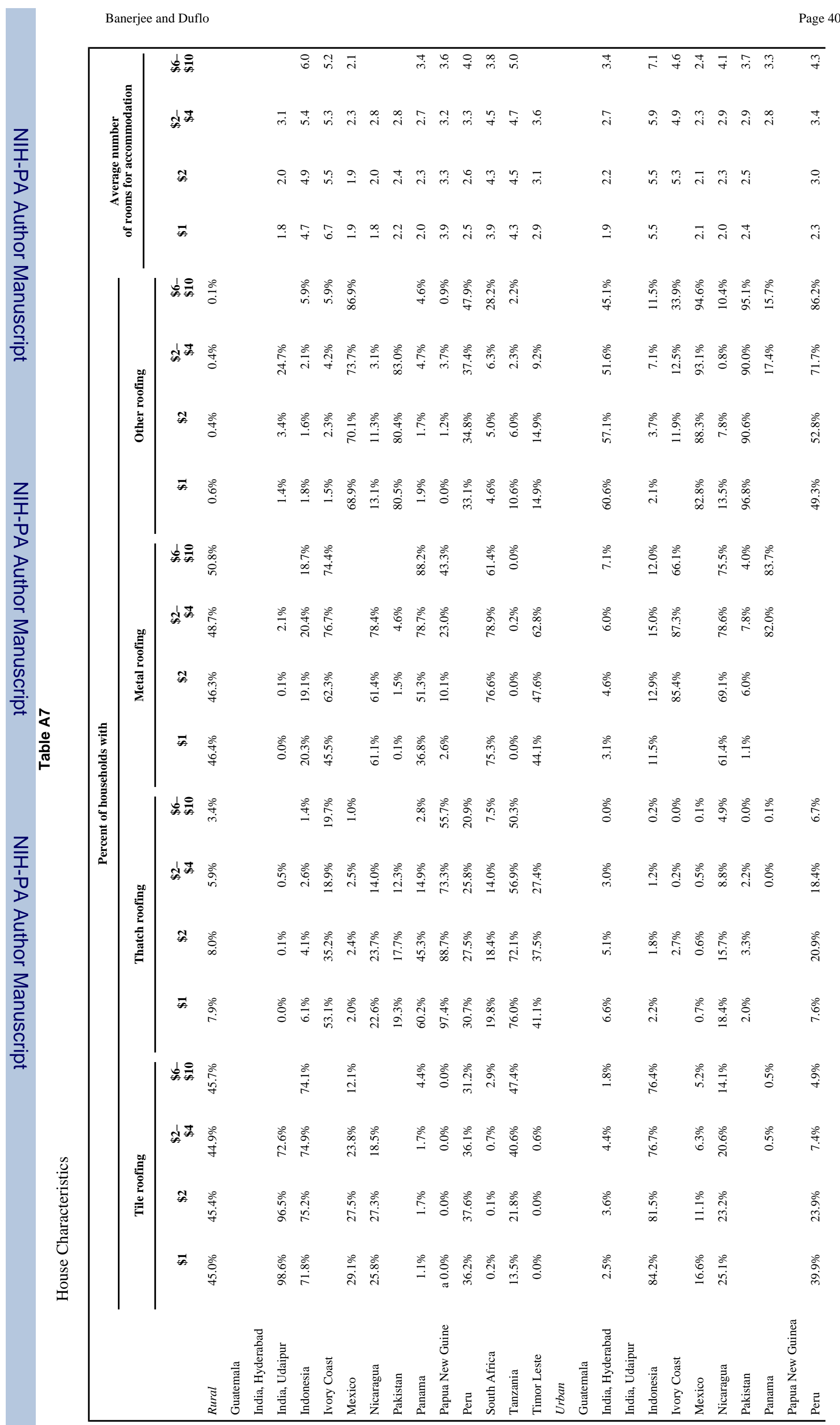




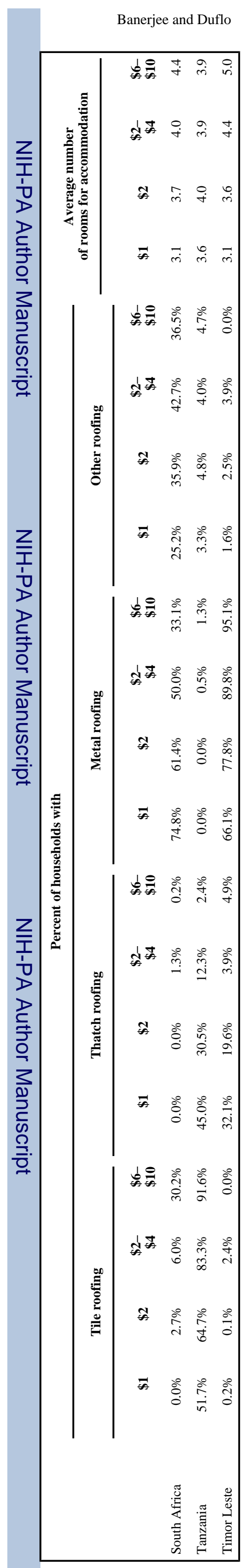




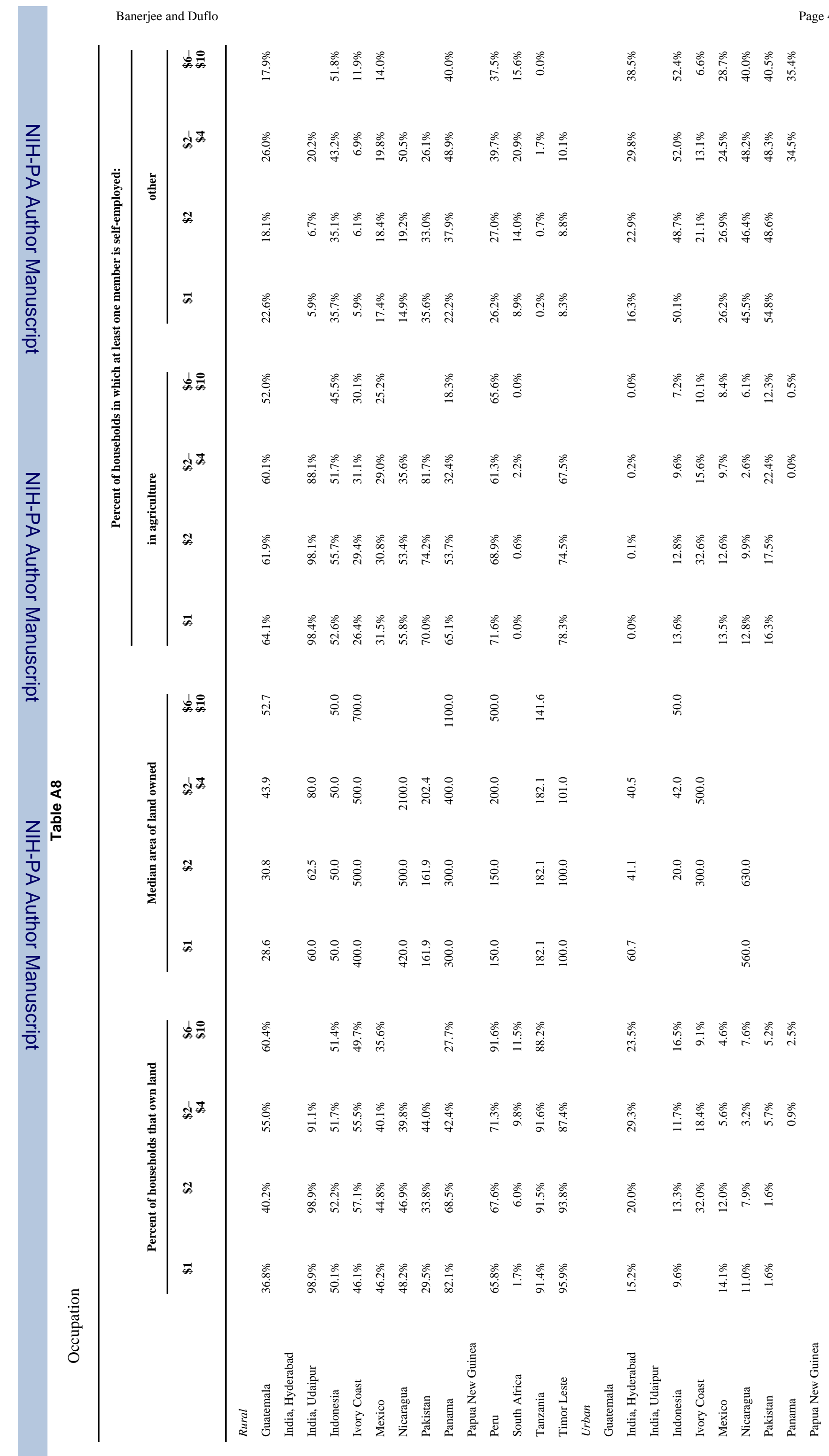




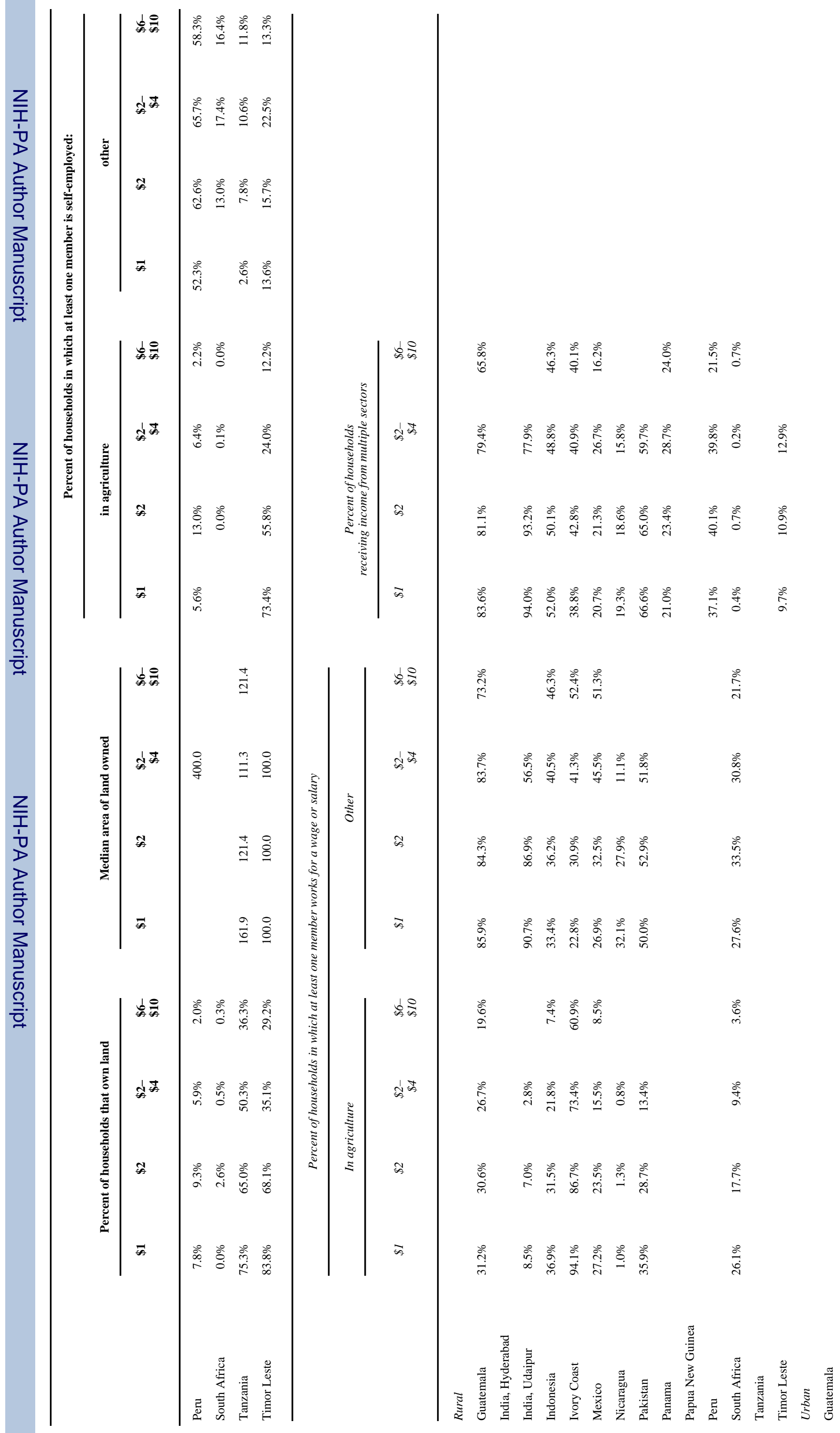




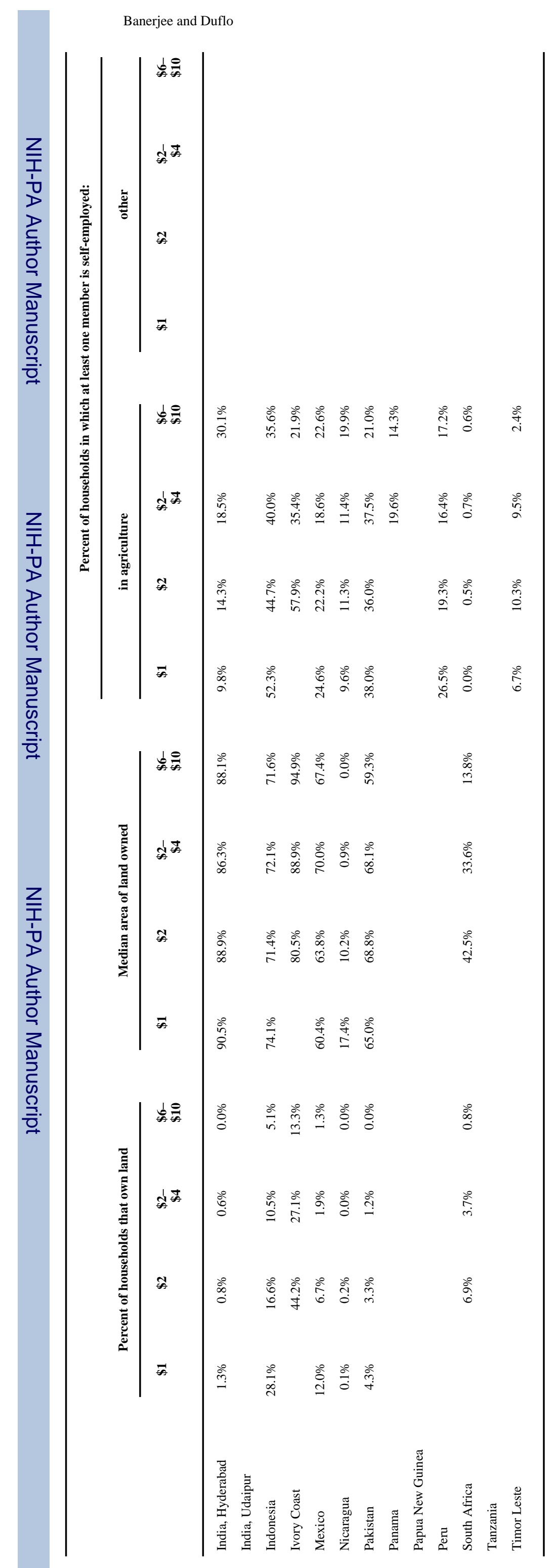

Page 44

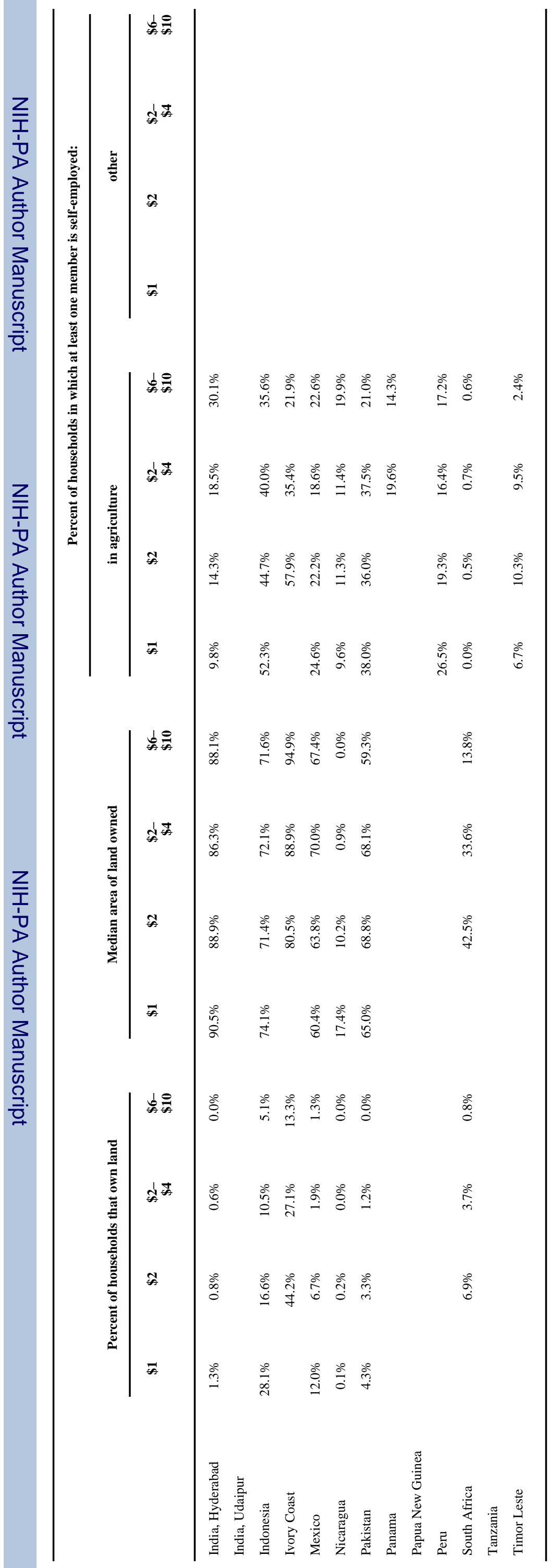




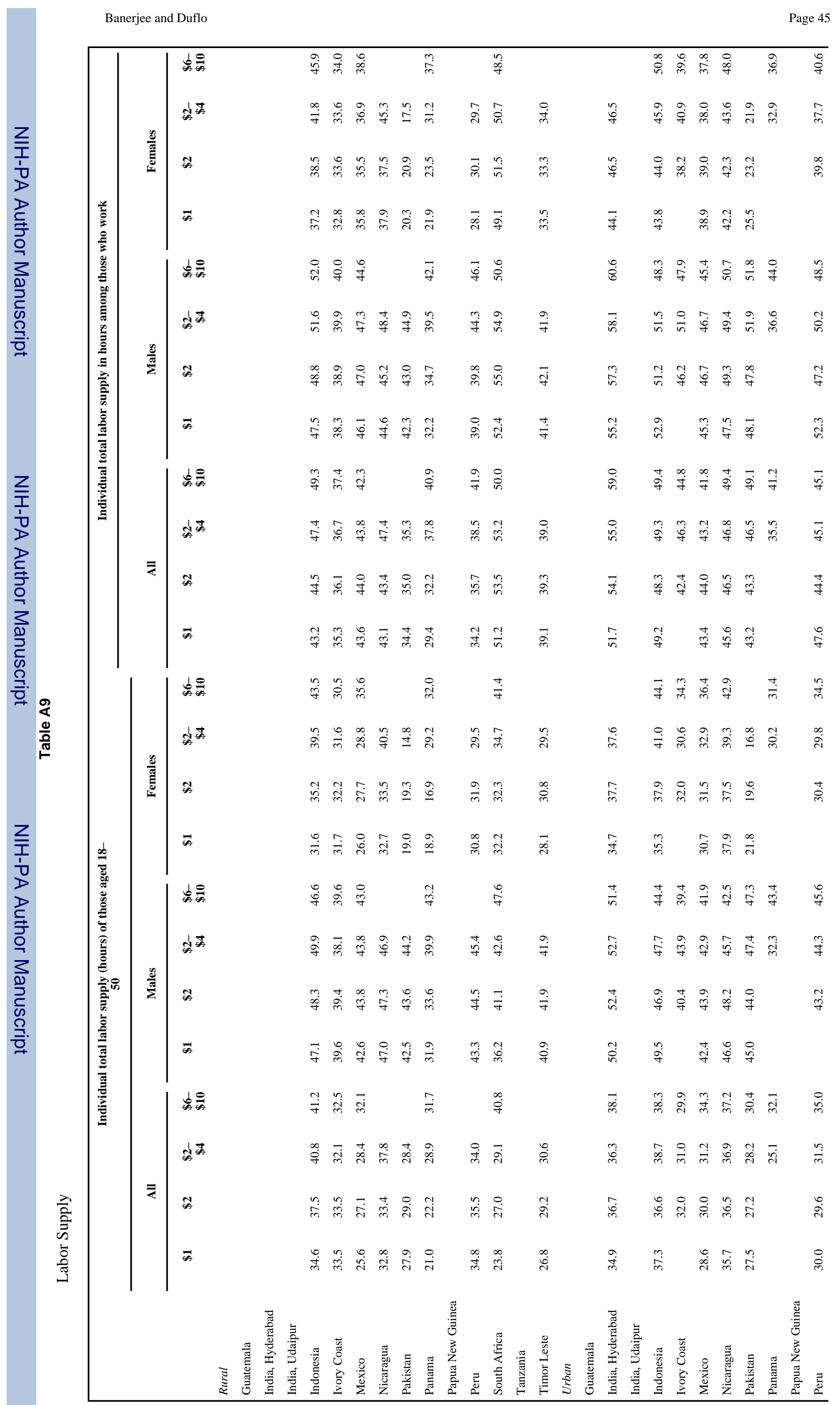




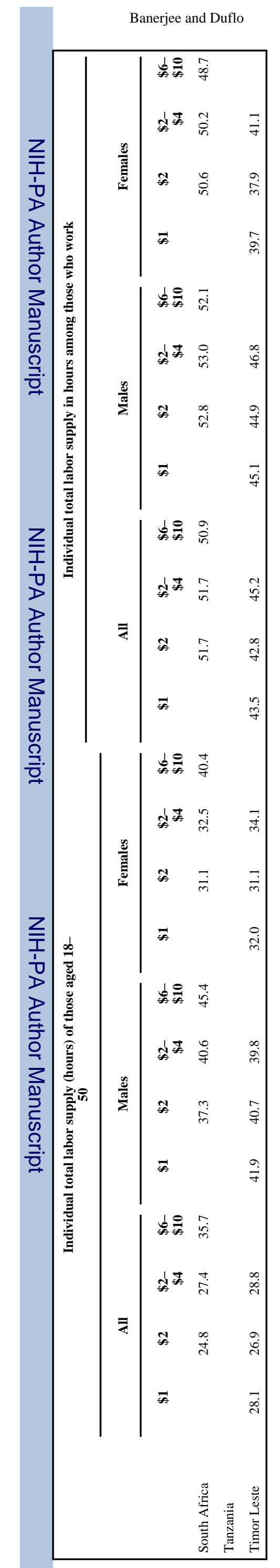

Page 46 


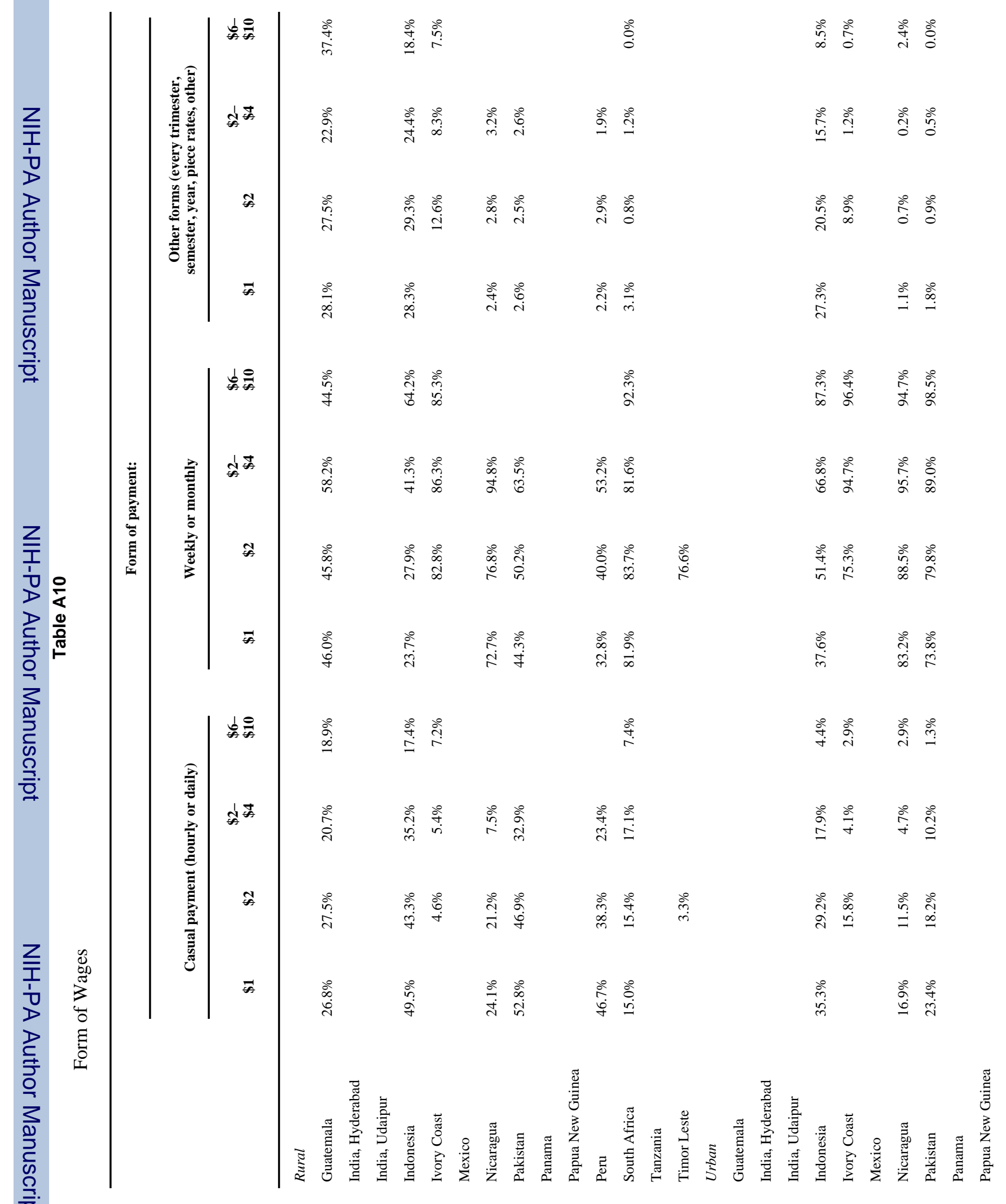




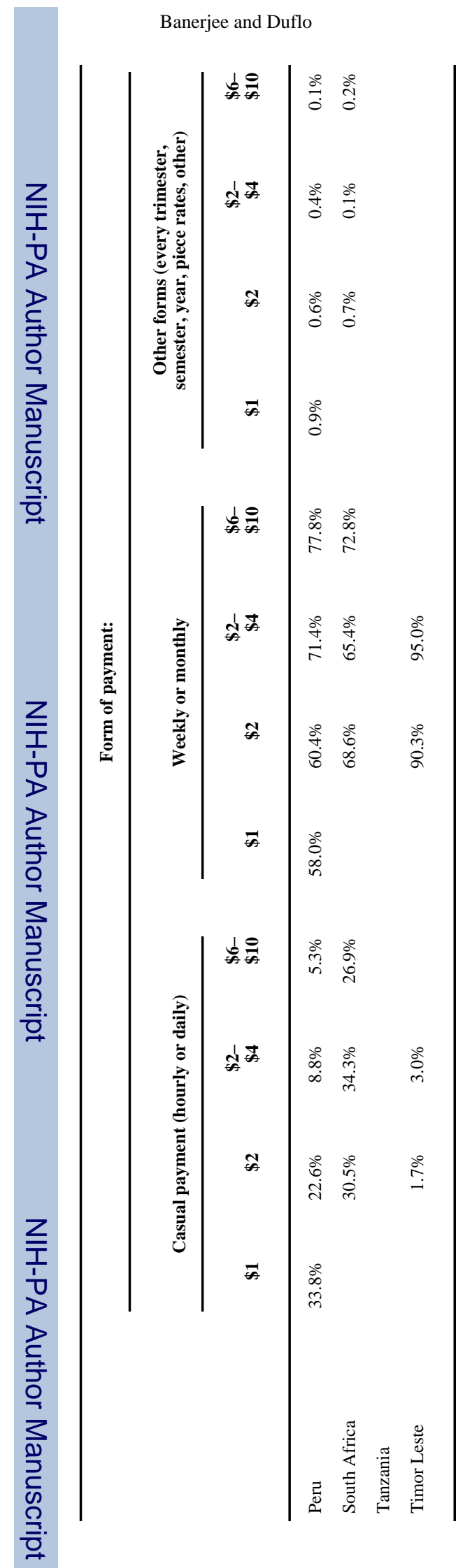

$J$ Econ Perspect. Author manuscript; available in PMC 2009 February 10. 


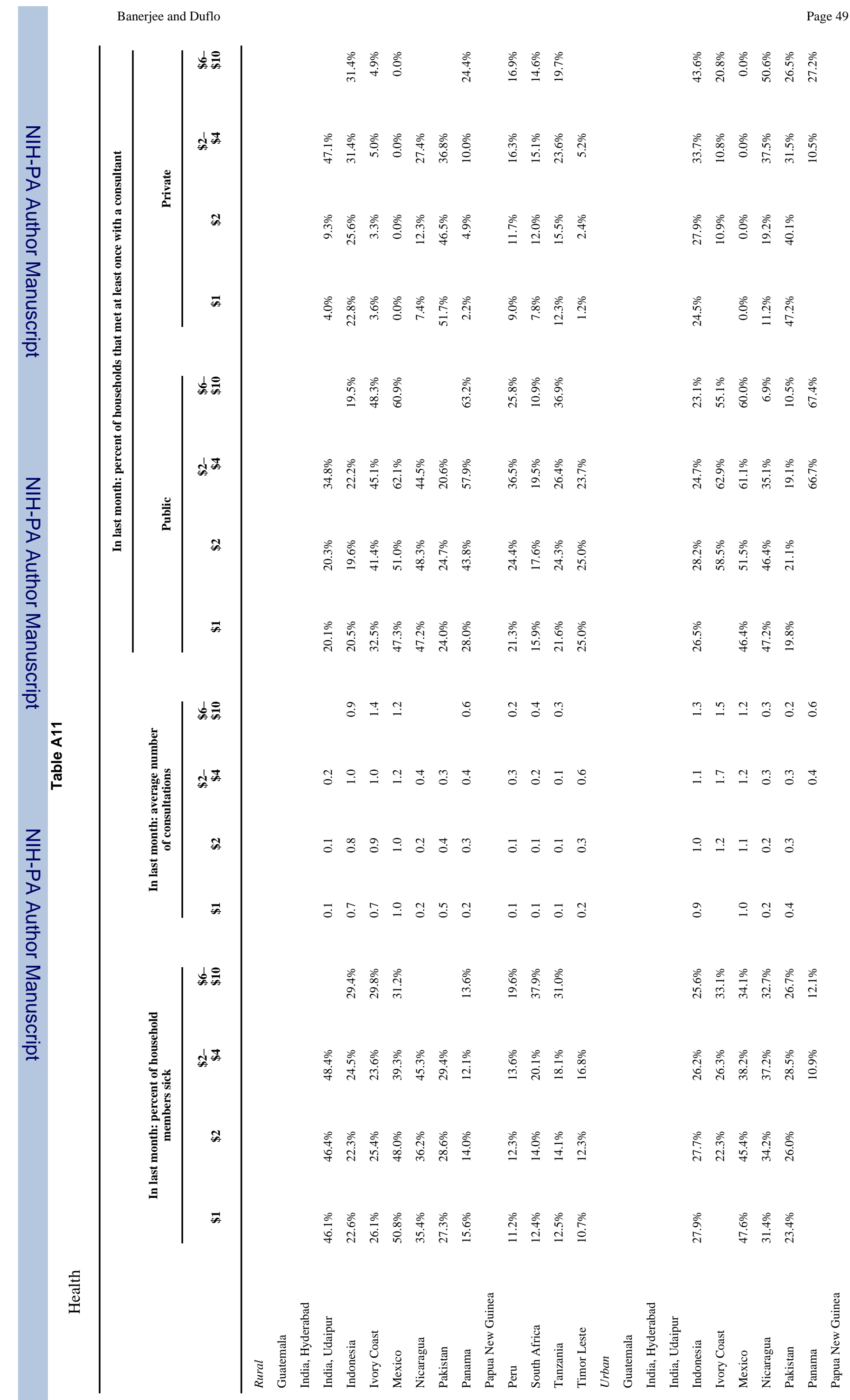




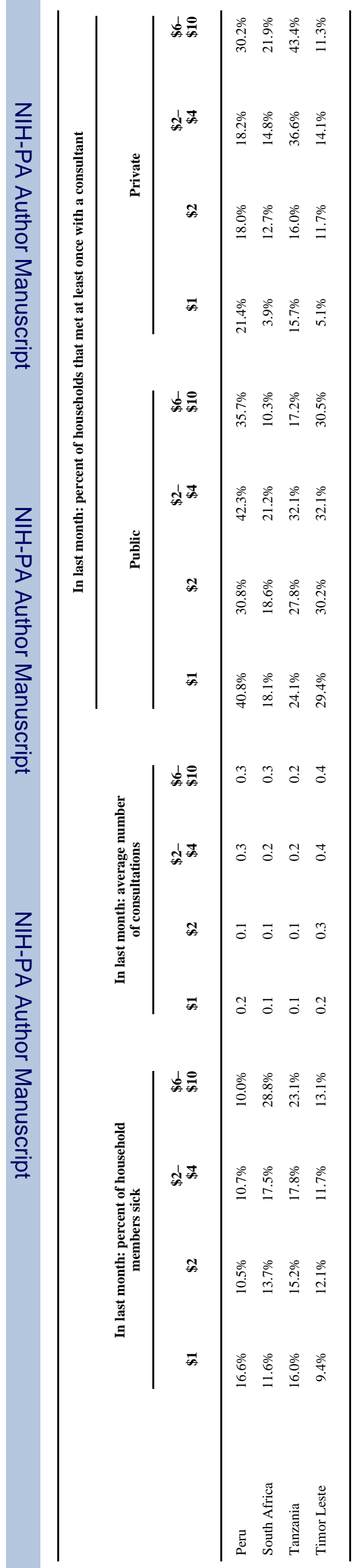




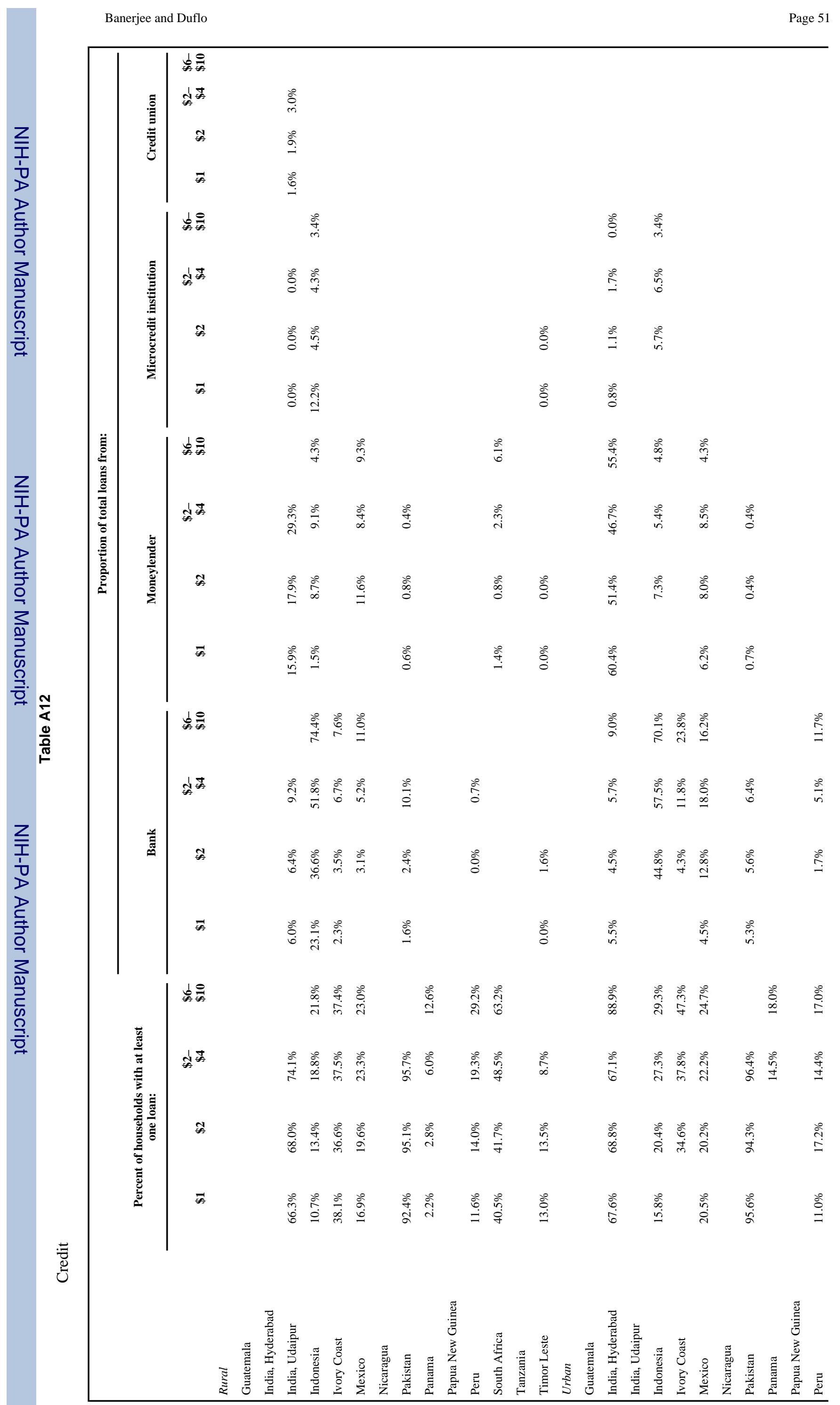




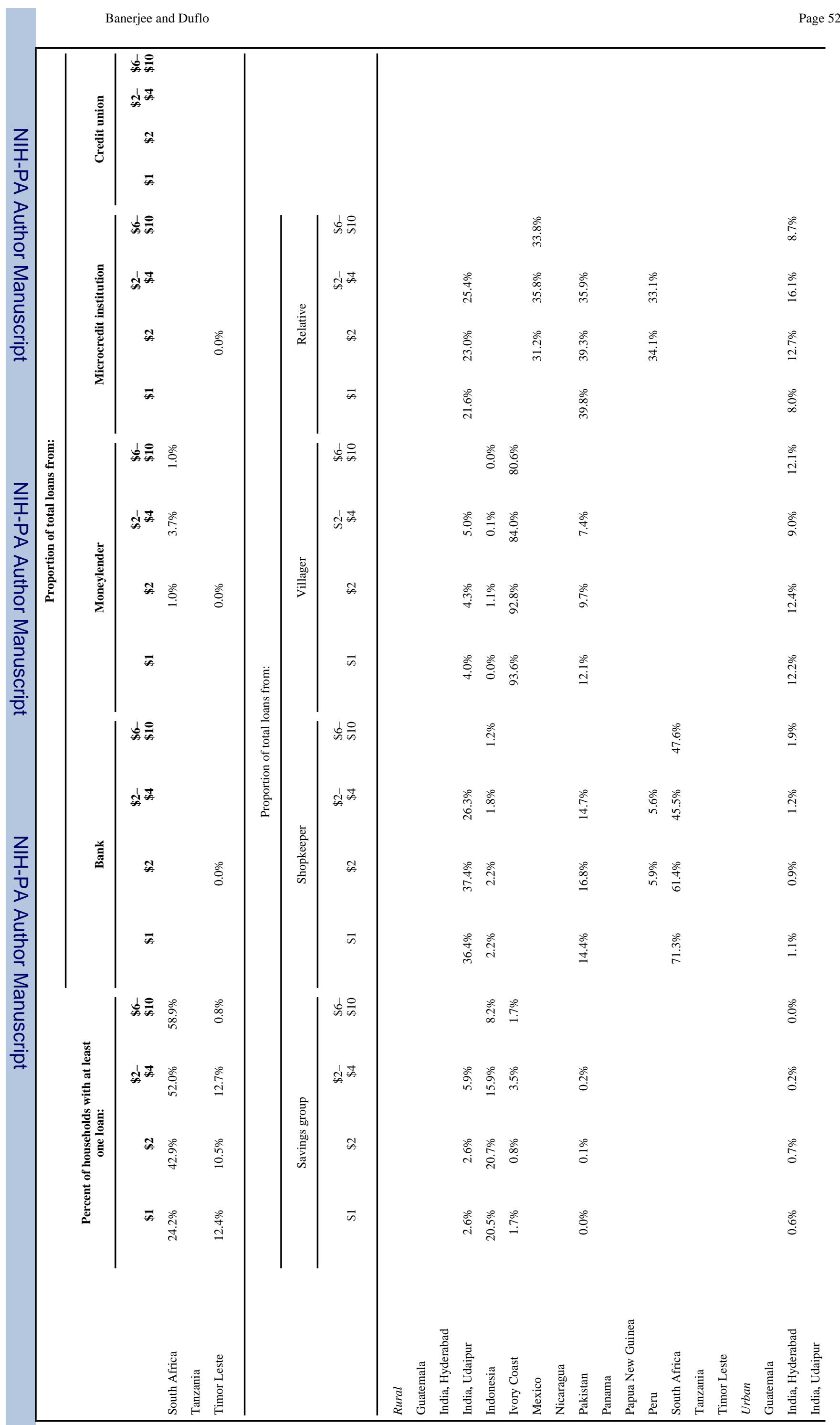




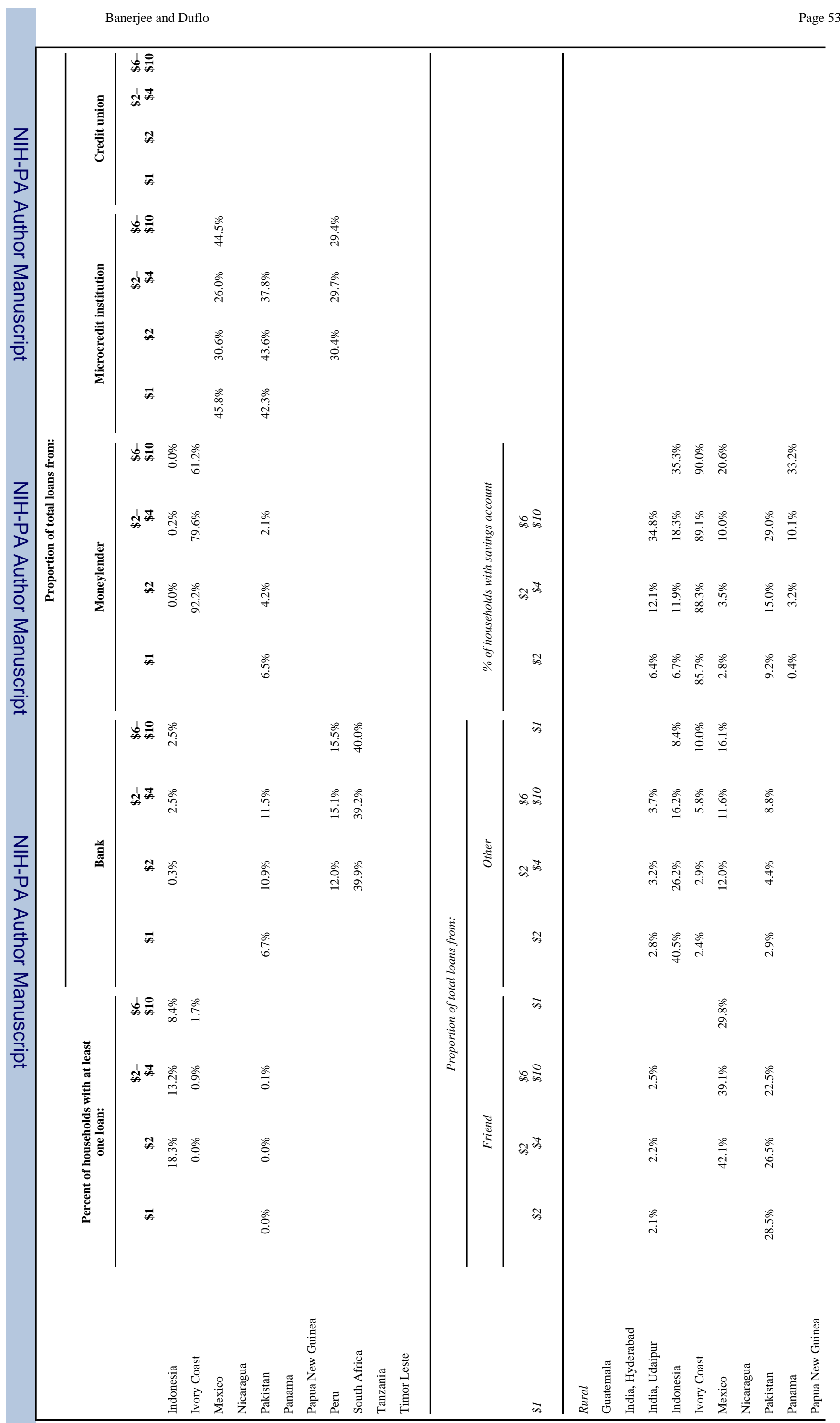




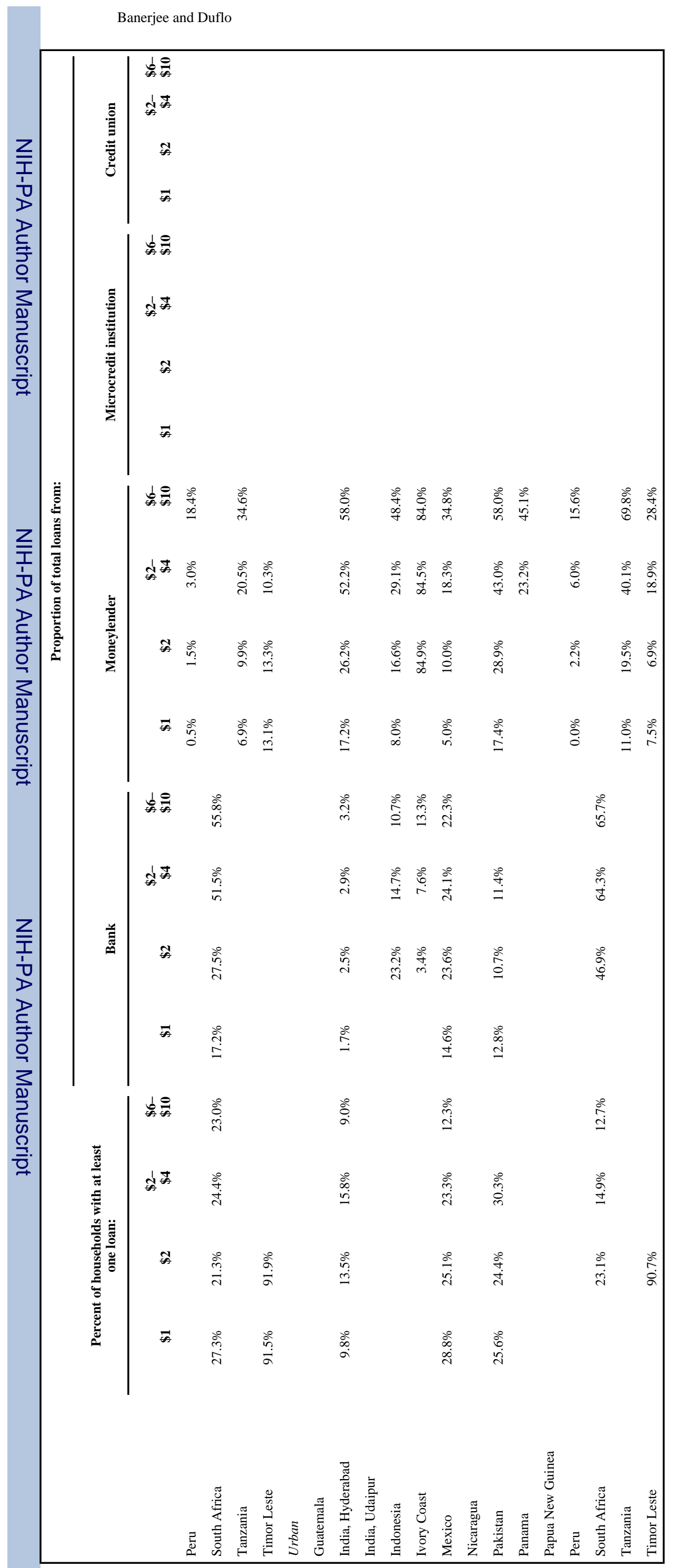

Page 54 


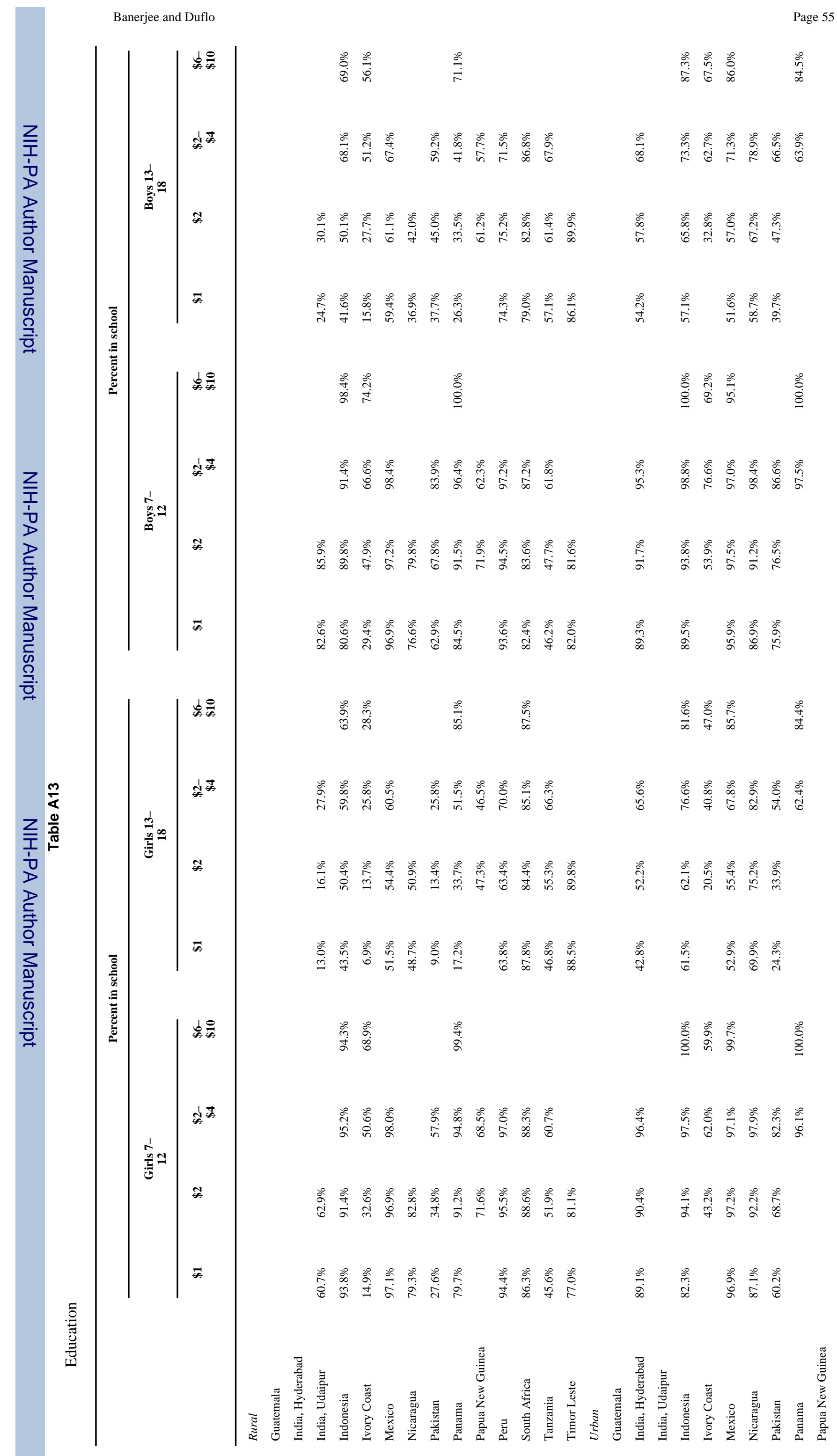




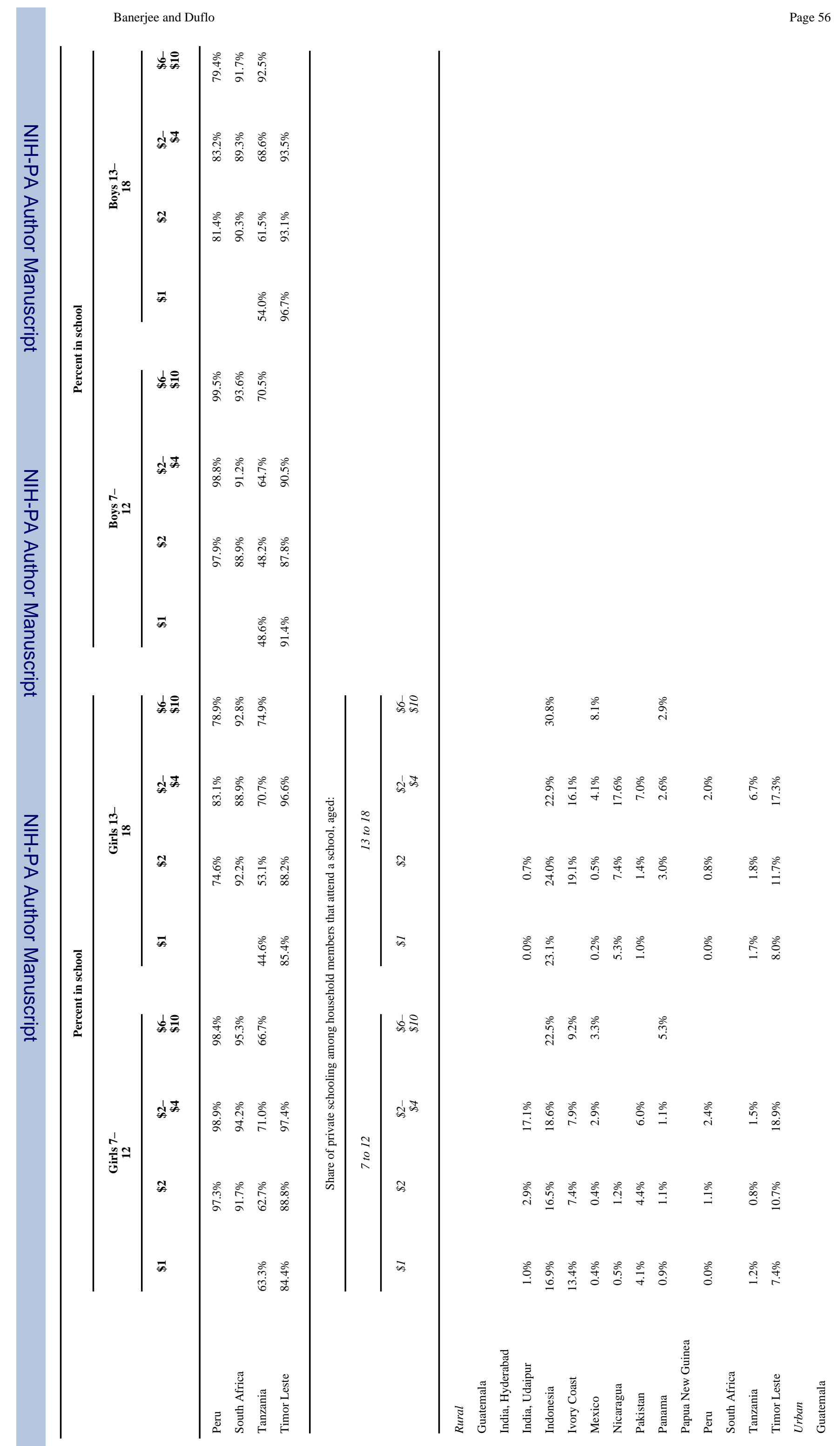




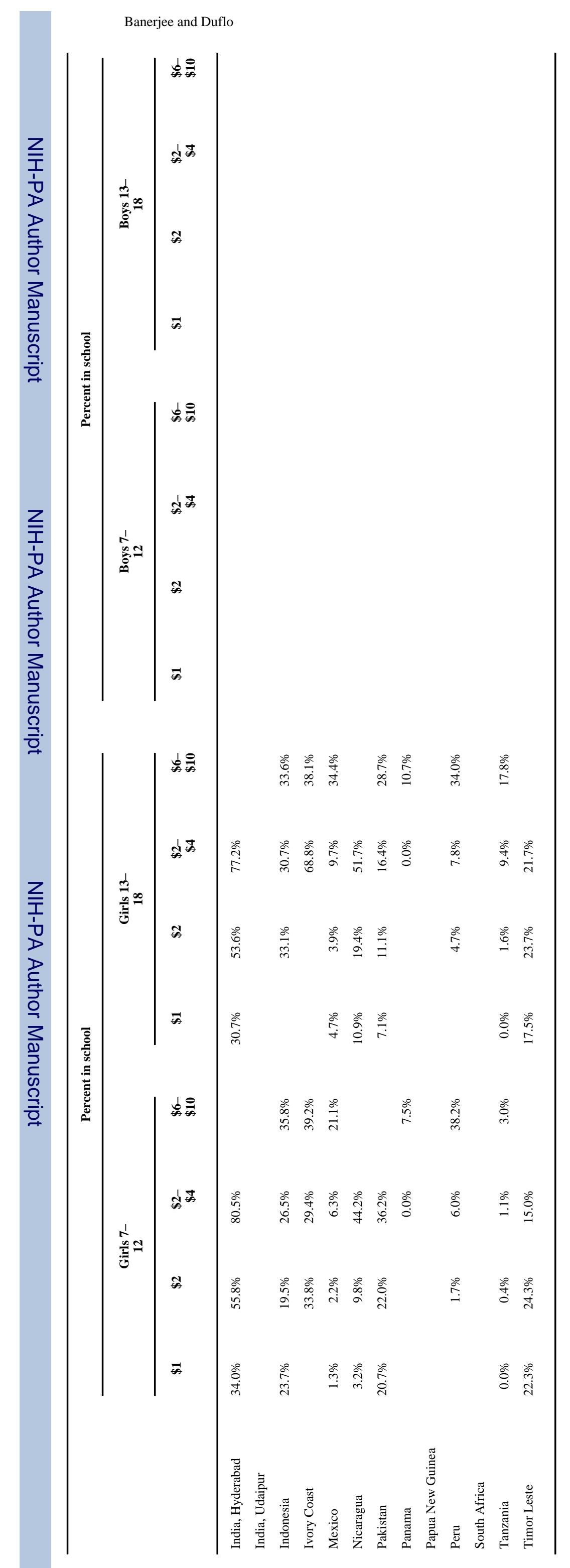

Page 57 


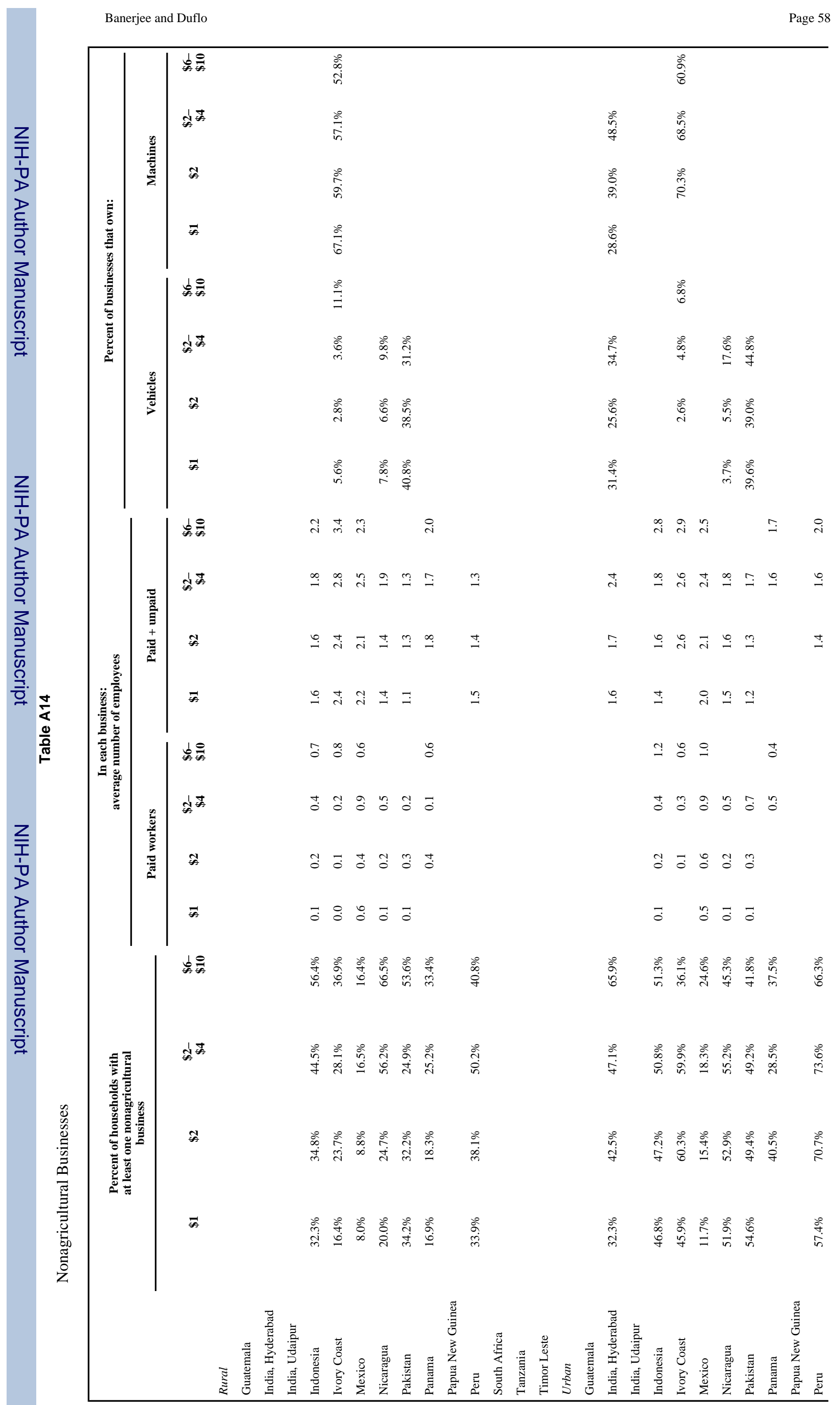




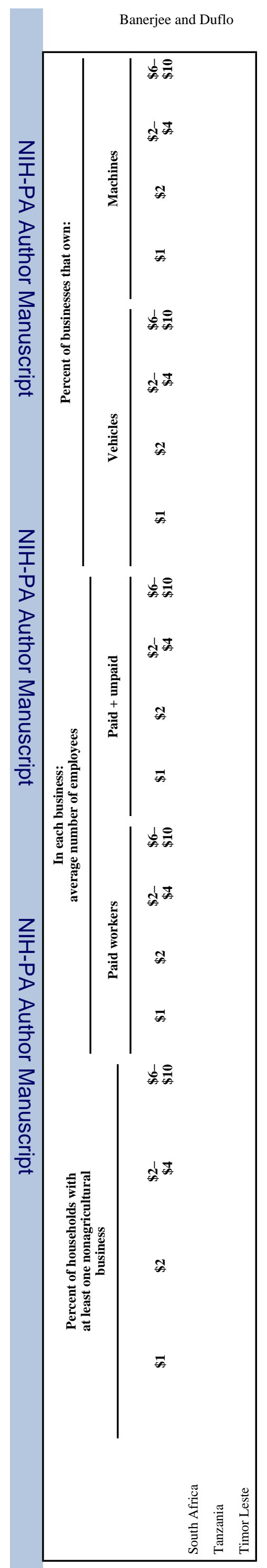

Page 59 


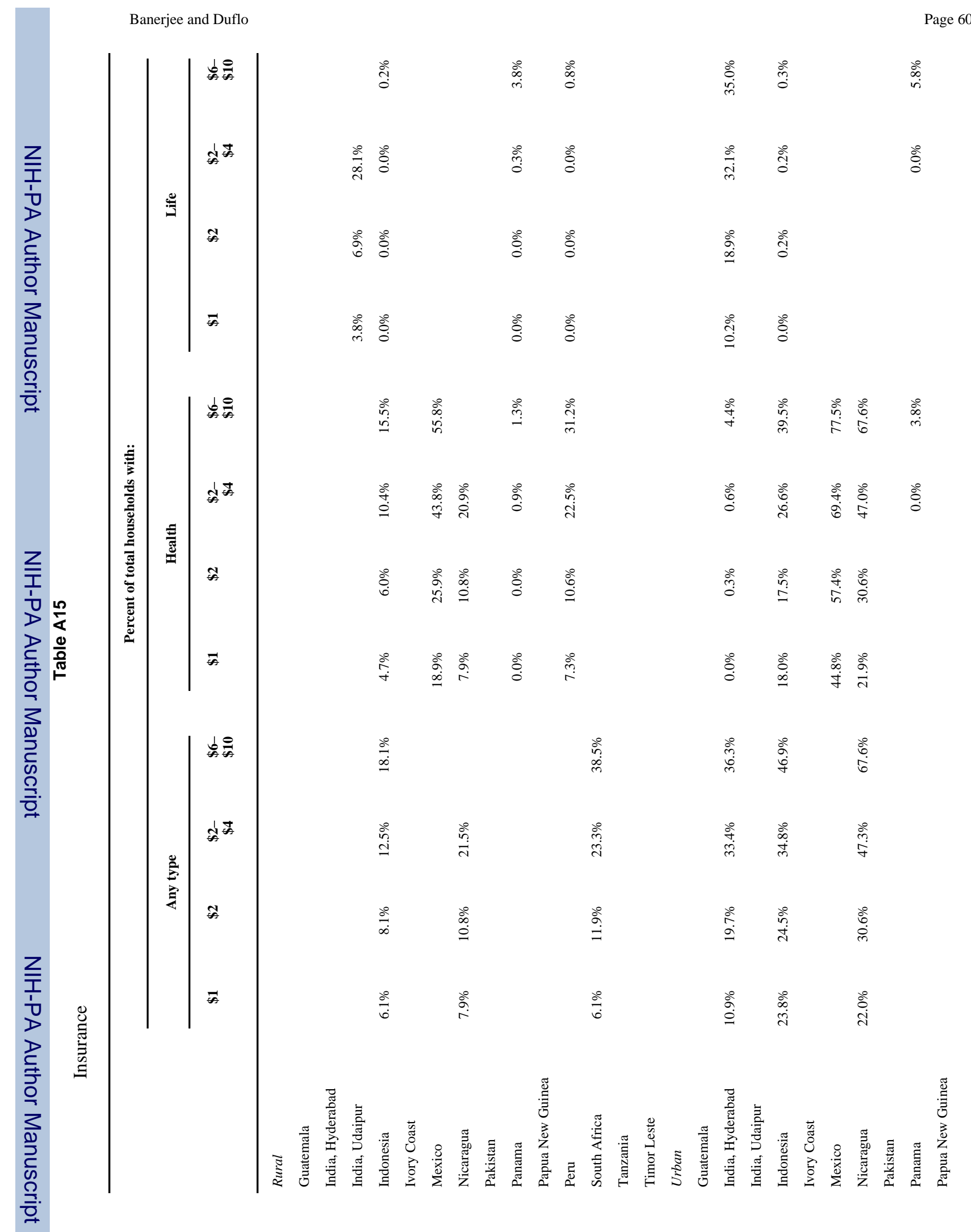




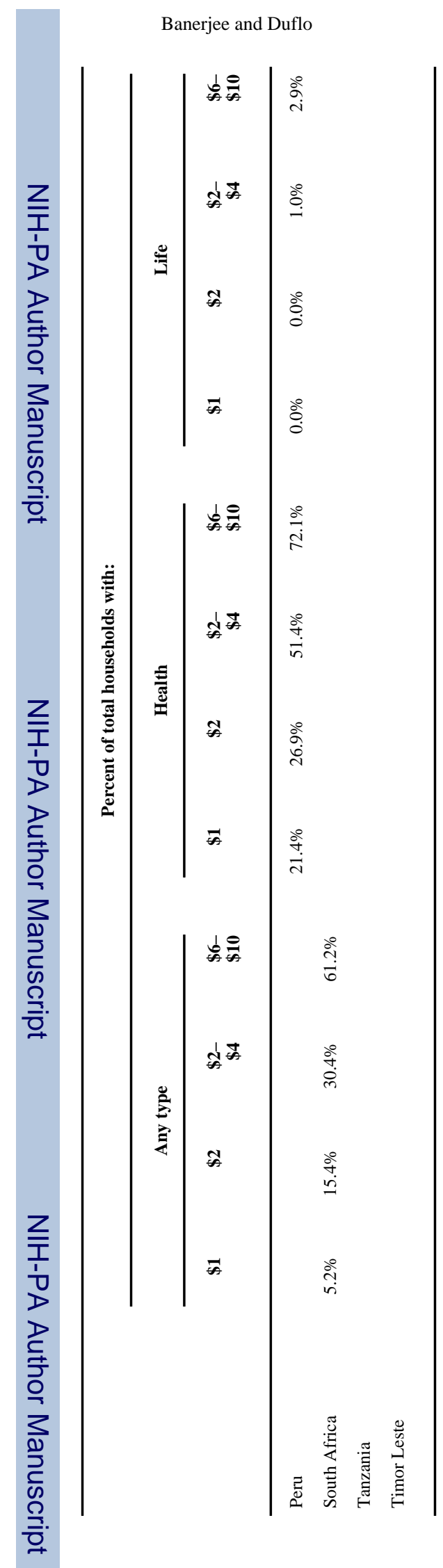

Page 61 


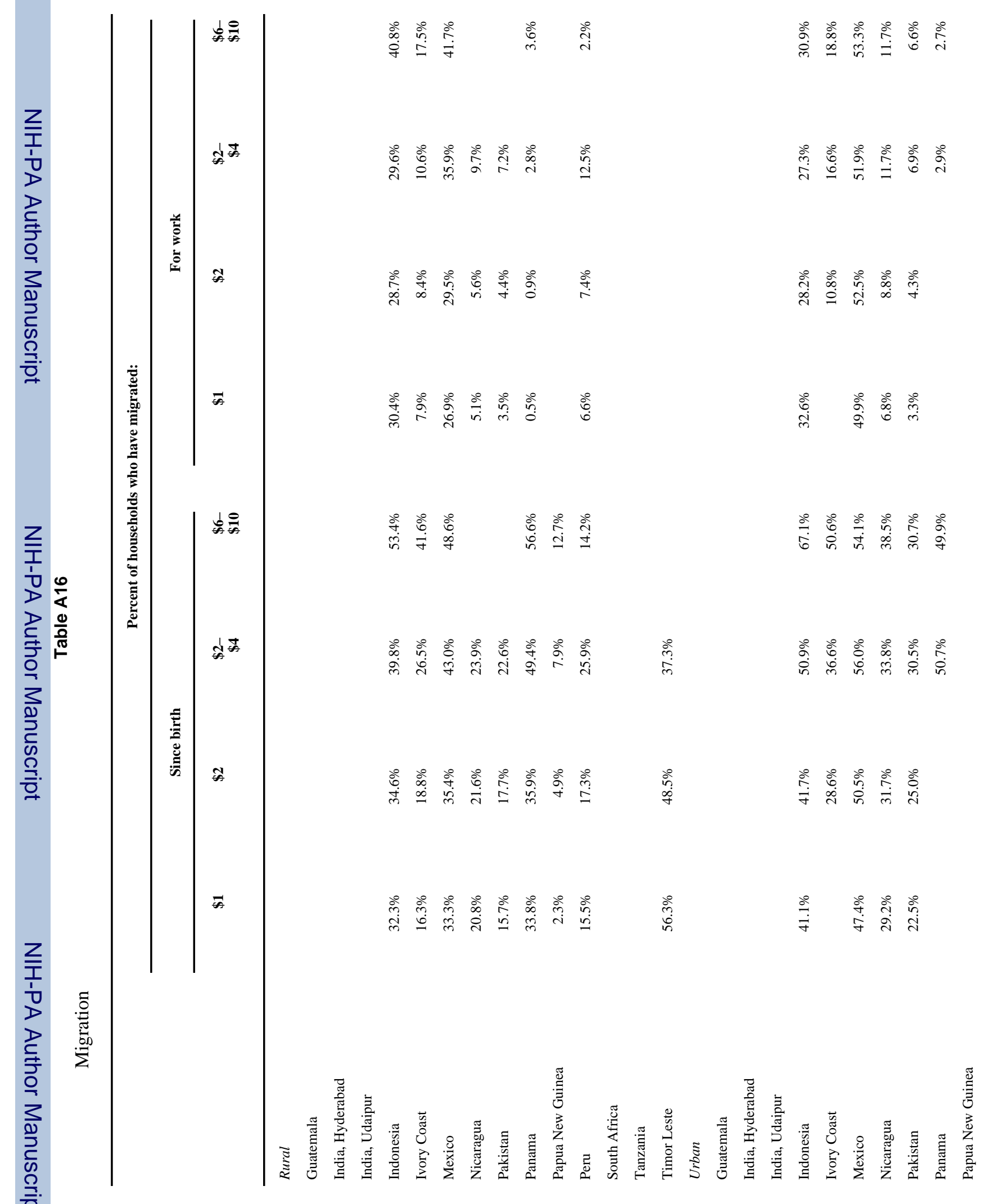




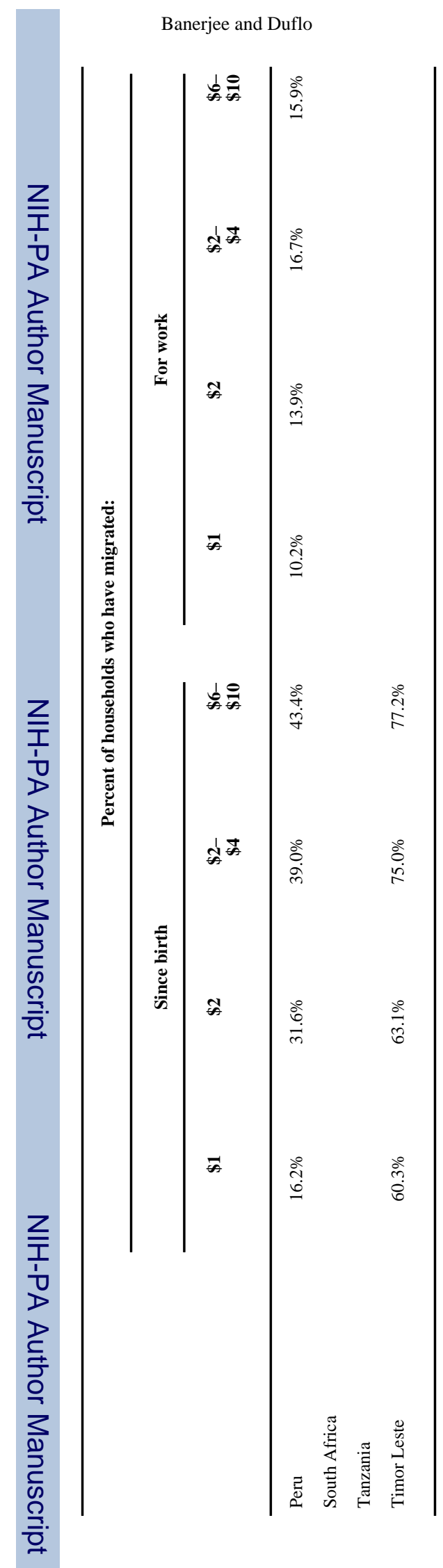

Page 63 